\title{
Habitat Quality Differentiation and Consequences for Ecosystem Service Provision of an Amazonian Hyperdominant Tree Species
}

\author{
Evert Thomas ${ }^{1 *}$, Merel Jansen ${ }^{2,3}$, Fidel Chiriboga-Arroyo ${ }^{2}$, Lúcia H. O. Wadt ${ }^{4}$, \\ Ronald Corvera-Gomringer ${ }^{5}$, Rachel Judith Atkinson ${ }^{1}$, Stephen P. Bonser ${ }^{6}$, \\ Manuel Gabriel Velasquez-Ramirez ${ }^{5}$ and Brenton Ladd ${ }^{7 *}$
}

${ }^{1}$ Bioversity International, Lima, Peru, ${ }^{2}$ Department of Environmental Systems Science, Institute of Terrestrial Ecosystems, Ecosystem Management, ETH Zürich, Zurich, Switzerland, ${ }^{3}$ Center for International Forestry Research -CIFOR, Lima, Peru, ${ }^{4}$ Embrapa Rondônia, Porto Velho, Brazil, ${ }^{5}$ Instituto de Investigaciones de la Amazonia Peruana - IIAP, Puerto Maldonado, Peru, ${ }^{6}$ School of Biological, Earth and Environmental Science, Ecology \& Evolution Research Centre, University of New South Wales, Sydney, NSW, Australia, ${ }^{7}$ Escuela de Agroforestería, Universidad Cientifica del Sur, Lima, Peru

OPEN ACCESS

Edited by:

Raquel Alfaro Sanchez, Wilfrid Laurier University, Canada

Reviewed by:

Georgina Conti,

Instituto Multidisciplinario de Biologia Vegetal (IMBIV), Argentina Shalik Ram Sigdel,

Institute of Tibetan Plateau Research (CAS), China

*Correspondence: Evert Thomas evert.thomas@gmail.com Brenton Ladd bladd@cientifica.edu.pe

Specialty section: This article was submitted to Functional Plant Ecology, a section of the journal

Frontiers in Plant Science

Received: 24 October 2020 Accepted: 03 March 2021 Published: 31 March 2021

Citation:

Thomas E, Jansen $M$, Chiriboga-Arroyo F, Wadt $L H O$ Corvera-Gomringer R, Atkinson RJ, Bonser SP, Velasquez-Ramirez MG and Ladd B (2021) Habitat Quality Differentiation and Consequences for Ecosystem Service Provision of an Amazonian Hyperdominant Tree Species. Front. Plant Sci. 12:621064. doi: 10.3389/fp/s.2021.621064
Ecosystem services of Amazonian forests are disproportionally produced by a limited set of hyperdominant tree species. Yet the spatial variation in the delivery of ecosystem services by individual hyperdominant species across their distribution ranges and corresponding environmental gradients is poorly understood. Here, we use the concept of habitat quality to unravel the effect of environmental gradients on seed production and aboveground biomass (AGB) of the Brazil nut, one of Amazonia's largest and most long-lived hyperdominants. We find that a range of climate and soil gradients create trade-offs between density and fitness of Brazil nut trees. Density responses to environmental gradients were in line with predictions under the Janzen-Connell and Herms-Mattson hypotheses, whereas tree fitness responses were in line with resource requirements of trees over their life cycle. These trade-offs resulted in divergent responses in area-based seed production and AGB. While seed production and AGB of individual trees (i.e., fitness) responded similarly to most environmental gradients, they showed opposite tendencies to tree density for almost half of the gradients. However, for gradients creating opposite fitness-density responses, area-based seed production was invariable, while trends in area-based AGB tended to mirror the response of tree density. We conclude that while the relation between environmental gradients and tree density is generally indicative of the response of AGB accumulation in a given area of forest, this is not necessarily the case for fruit production.

\footnotetext{
Keywords: spatial aggregation, Bertholletia excelsa, carbon sequestration, growth differentiation balance framework, Janzen-Connell hypothesis, negative density dependence (NDD), ecosystem service trade-offs,
} environmental gradients

\section{INTRODUCTION}

Amazonian rainforests generate vital ecosystem services (Strand et al., 2018). They harbor the largest plant biodiversity on Earth (ter Steege et al., 2013), represent the biggest pool of tropical carbon (Brienen et al., 2015), and are an important source of timber (Rutishauser et al., 2015) and non-timber products (Shackleton et al., 2011). While the remarkable diversity of these 
forests undoubtedly plays a role in the generation of ecosystem services (Cardinale et al., 2011; Poorter et al., 2015; Liang et al., 2016), there is increasing evidence that some services, such as wood production and carbon storage, are disproportionally produced by a small number of hyperdominant tree species that are extremely common and abundant in one or more Amazonian forest regions (ter Steege et al., 2013; Fauset et al., 2015). However, the spatial variation in the delivery of ecosystem services by individual hyperdominant species across their distribution ranges and corresponding environmental gradients remains understudied.

The amount of ecosystem services generated in a given area of forest by a tree species is governed by the combination of the number of individual trees in that area (population density) (Winfree et al., 2015; Gaston et al., 2018) and the state and performance of the individual trees such as tree growth, survival, and reproduction (Figure 1). The reproductive success of tropical trees is vital for maintaining healthy recruitment levels and supporting forest food chains (Staggemeier et al., 2017), and also for the sustainability of non-timber forest product (NTFP) extractive economies. Tree survival over time and growth rate are generally associated with tree size (Rozendaal and Zuidema, 2011), and hence sequestration of carbon, a key ecosystem service for climate regulation and wood production. Therefore, to understand the effect of spatial variation on the delivery of ecosystem services by a tree species, one must understand how tree density and individual tree performance vary along environmental gradients.

The concept of habitat quality offers a powerful framework to analyze this. Habitat quality is a measure of the probability that a particular habitat allows for the long-term persistence of a local population (Johnson, 2007; Oliver et al., 2012), with the key indicators of habitat quality for a given species being population density (Pimm et al., 1988; Gutiérrez et al., 2013) and fitness. Fitness can be measured as an individual's contribution to population persistence and is the combination of tree performance in terms of reproductive success (fertility), growth (Jansen et al., 2012), and survival (Bradshaw and McMahon, 2008; Bean et al., 2014). The ecosystem services that a tree species provides in a certain area thus are to a large extent dependent on the habitat quality of the area. However, within habitat quality there may be differentiation; i.e., tree density and fitness may be negatively correlated, and different fitness measures may not all be positively correlated among each other. Such differentiation of habitat quality is well-documented in animal species (Johnson, 2007). For example, in bird species, increasing population density has been shown to diminish the average fecundity of breeding pairs (Rodenhouse et al., 2003), but in tropical tree species, this mechanism remains understudied.

An important indication of the differentiation of densityand fitness-related measures in tropical tree species is the pervasive manifestation of conspecific negative distance or density-dependent (CNDDD) effects on the recruitment (Harms et al., 2000; Comita et al., 2014; LaManna et al., 2017), survival (He and Duncan, 2000; Hubbell et al., 2001; Zhang et al., 2009), growth (Uriarte et al., 2004), and fruit production (AlvarezBuylla, 1994; Jones and Comita, 2008; Thomas et al., 2017, 2018) of tree species around the world. CNDDD effects on tree recruitment are explained by the Janzen (1970)-Connell (1971) hypothesis, which predicts that host-specific seed predators, herbivores, and pathogens are attracted to seeds, seedlings, and juvenile plants at high density or close to adult conspecifics, resulting in a higher mortality compared with other situations. CNDDD effects on the fitness of adult trees, on the other hand, have been related to intraspecific competition for resources and fine-scale genetic structuring (Hubbell et al., 2001; Jones and Comita, 2008; Thomas et al., 2018).

Furthermore, habitat quality measures at the level of individuals (tree-centric) and populations (area-based) are expected to show idiosyncratic responses to environmental gradients that exist across tree species distribution ranges. For example, individual tree growth and reproductive success have been found to respond differently to environmental variables in Neotropical tree species in accordance with different resource requirements and environmental tolerance limits throughout the trees' life cycles (Staudhammer et al., 2013; AlfaroSánchez et al., 2017). Variation in conspecific tree density and aggregation across environmental gradients, on the other hand, is partly related to environmentally controlled CNDDD effects of recruitment (Bachelot et al., 2016; LaManna et al., 2016, 2017). High rainfall and low seasonality in the tropics favor desiccation-intolerant insects and fungi that are directly responsible for promoting high rates of CNDDD plant mortality (Janzen, 1970; Connell, 1971). On the other hand, infertile soils or unfavorable rooting conditions tend to favor greater allocation to anti-herbivore defenses in trees, which leads to lower rates

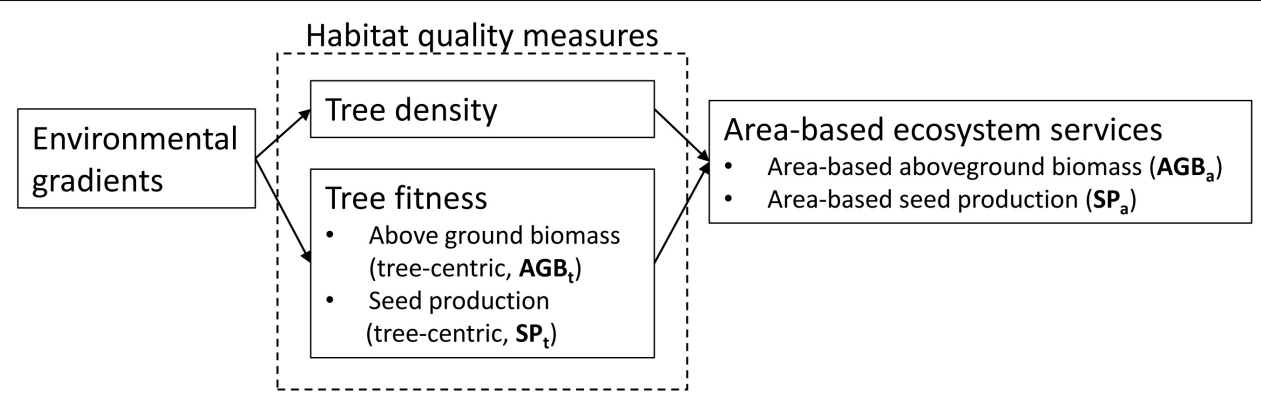

FIGURE 1 | Conceptual representation of the relation between environmental gradients, habitat quality measures, and area-based ecosystem services. 
of pest- and disease-related mortality (Givnish, 1999). This is explained by the hypothesis of Herms and Mattson (1992), which postulates that plant defense is premised upon a physiological trade-off between growth (cell division and enlargement) and differentiation (chemical and morphological changes leading to cell maturation and specialization, including synthesis of defense compounds), referred to as the growth differentiation balance framework. Nutrient and light-rich conditions favor growth at the expense of defense compounds to enhance a plant's competitive advantage. By contrast, in resource-limited environments, several factors interact to favor the selection of high levels of secondary metabolism (Herms and Mattson, 1992). In accordance with the Janzen-Connell and HermsMattson hypotheses, precipitation (Comita et al., 2014) and soil fertility (LaManna et al., 2016) have been found to positively influence CNDDD effects on tree recruitment and hence lower conspecific tree density and aggregation (Comita et al., 2010; Mangan et al., 2010).

The question remains as to how different responses to environmental gradients of area-based (density) and tree-centric (fitness) habitat quality indicators might influence the potential provision of ecosystem services by a tree species in a given area of forest. In this study, we test two hypotheses. The first hypothesis is that the relationships between environmental gradients and ecosystem service generation of a tree species in a given area of forest mirror those of its density, regardless of possible divergent responses of fitness variables (cf. Winfree et al., 2015; Gaston et al., 2018). The second hypothesis we test is that conspecific density responds to environmental gradients in line with the predictions under the Janzen-Connell and Herms-Mattson hypotheses, while fitness variables respond to environmental gradients in line with niche preferences and resource requirements throughout a tree's life cycle. More specifically, we expect environmental conditions that favor pests and diseases (higher precipitation and air temperatures and lower seasonality) and disfavor plant defense mechanisms against these (higher soil fertility and lower soil density) to be associated with lower tree densities. By contrast, higher soil fertility and precipitation are expected to positively influence seed production and biomass accumulation of individual trees, while higher air temperature is anticipated to have a negative influence on these variables in line with findings for tree species around the world (Feeley et al., 2007; Clark et al., 2010, 2016; Pérez-Ramos et al., 2010; Rozendaal and Zuidema, 2011; Girard et al., 2012; Wagner et al., 2014; Alfaro-Sánchez et al., 2017).

We test these hypotheses for the Brazil nut tree (Bertholletia excelsa, an Amazonian hyperdominant), using the fitness measures seed production and aboveground biomass (AGB). As the estimated seed production and AGB of focal Brazil nut trees have been found to be negatively influenced by both the density and spatial aggregation of their conspecific neighborhoods, which are not linearly correlated (Thomas et al., 2018), we additionally assessed the relation between spatial aggregation and environmental variables. Spatial aggregation is not considered as a measure of habitat quality, but if environmental gradients on Brazil nut tree density reflect CNDDD effects, spatial aggregation is expected to show congruent trends.

\section{MATERIALS AND METHODS}

\section{Study Species}

The Brazil nut tree is an emergent of up to $60 \mathrm{~m}$ tall and one of the largest and most long-lived of all hyperdominant tree species in Amazonia (Vieira et al., 2005; ter Steege et al., 2013; Schöngart et al., 2015). Brazil nut trees not only play a keystone role in the ecology and nutrient cycling of Amazonian forests (Wadt et al., 2005) but have also supported human livelihoods since the peopling of the Amazon basin (Shepard and Ramirez, 2011; Thomas et al., 2015). Brazil nut seed remains a cornerstone NTFP in Amazonia, and the species plays a pivotal role in carbon sequestration (Fauset et al., 2015; Selaya et al., 2017). Brazil nut has an aggregated distribution pattern due to the combined effects of short-distance seed dispersal by rodents (Haugaasen et al., 2010) and anthropogenic activities (Shepard and Ramirez, 2011; Thomas et al., 2014, 2015). However, different lines of evidence suggest that in Peru the effect of anthropogenic activities appears to have been minimal as compared with central and eastern Amazonia (Thomas et al., 2015; Rockwell et al., 2017; Porcher et al., 2018). Also, human harvesting of Brazil nut seeds is unlikely to negatively impact regeneration. A study in nearby Acre, Brazil, tracked the fate of almost 7,000 Brazil nut fruits right after falling on the ground and concluded that Brazil nut harvesting is unlikely to threaten recruitment (de Wadt et al., 2018). The main reason for this is that (1) harvesters typically enter the forest only after most fruits have fallen (over a 3-month period) because of the big risk of being injured (or killed) by falling fruits and (2) the main dispersers (agoutis) typically open fruits within days after falling.

Figure 2 shows the phenology of the Brazil nut in the study regions based on Corvera-Gomringer et al. (2010) and the authors' personal long-term observations. As the fruits take 1214 months to mature, there are several critical phases throughout the year where climate variables may influence flowering, fruit set, and fruit growth and development. Furthermore, the Brazil nut has a semi-deciduous behavior in the study region, and the species typically starts shedding leaves at the end of the dry season, and new leaf growth occurs throughout the warmest quarter of the year, suggesting that precipitation and air temperature in these periods of the year might influence biomass accumulation.

\section{Data}

We used georeferenced data of 192,849 Brazil nut trees with diameter at breast height $(\mathrm{DBH}) \geq 10 \mathrm{~cm}$ from 544 Brazil nut concessions in Madre de Dios, Peru, with an average size of 761 ha (range 164-575 ha; Figure 3). Data were collected from 2003 to 2007, in response to the Peruvian Forestry Law No. 27308 (5/10/2001), which obliged concession holders for the first time to present detailed inventories of the Brazil nut trees under their custody. The inventories were carried out by institutions active in the region, most notably ACCA (Asociación para la Conservación de la Cuenca Amazónica), CAMDE (Conservación Ambiental y Desarrollo en el Perú), FONDEBOSQUE (Fondo de Promoción del Desarrollo Forestal), 


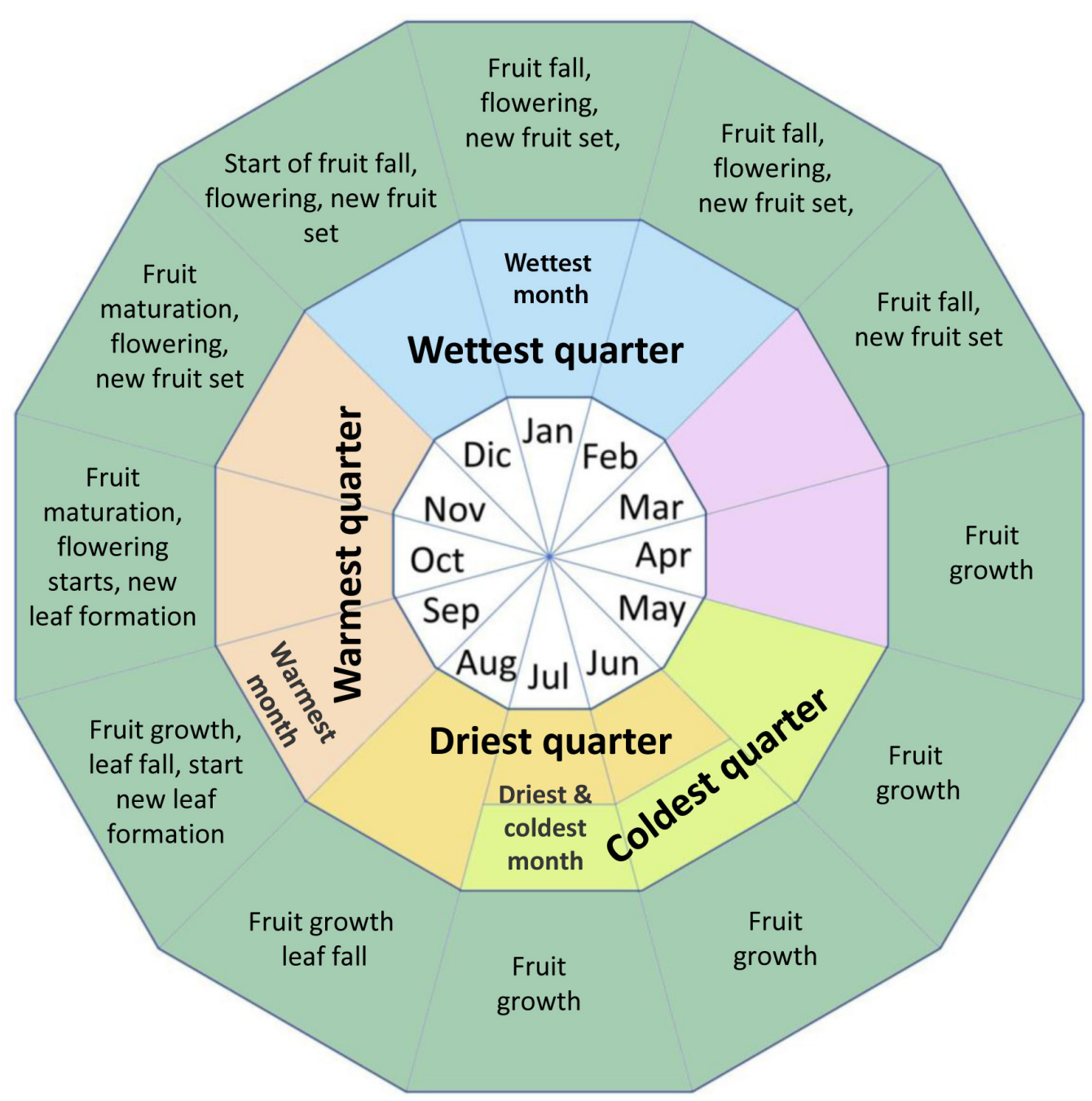

FIGURE 2 | Phenology of the Brazil nut in the study regions based on Corvera-Gomringer et al. (2010) and the authors' personal long-term observations.

AIDER (Asociación para la Investigación y el Desarrollo Integral), RNTAMB PRMRFFS (Programa Regional de Manejo de Recursos Forestales y Fauna Silvestre), Forestal Rio Piedras SAC, and Conservation International. Field staff from these institutions georeferenced individual trees, for the majority of these trees measured height and DBH (120,105 trees), and asked Brazil nut harvesters who accompanied them to estimate the average productivity of each individual tree (135,528 trees). For the vast majority of trees, these data were complemented with a description of each tree's phytosanitary condition, by indicating whether a tree was covered by lianas, had broken branches or holes in its trunk, or showed evidence of termite nests, wound exudate, or tumors. Brazil nut seeds are harvested by cracking open the lignified capsular fruits with a machete after they have fallen on the ground. Individual seeds are protected by wooden testa, but these are not opened in the field, and harvesters express seed production weight in terms of "latas" (tin cans), which contain approximately $11.66 \mathrm{~kg}$ of fresh inshell seeds. Previous analyses carried out with this dataset have demonstrated that seed production estimations by harvesters are reliable proxies of average production levels and that the data are robust enough to allow ecological hypothesis testing (Thomas et al., 2017, 2018). Annual seed production estimates of trees $\left(\mathrm{SP}_{\mathrm{t}}\right)$ varied from 0 to $362 \mathrm{~kg}$, with an average of $30.3 \pm 26.9$ (SD) $\mathrm{kg}$ per tree. Approximately $13 \%$ of all trees were claimed never to produce by concessionaires. We used the $\mathrm{DBH}$-based equations from Chave et al. (2014) to calculate AGB of individual Brazil nut trees $\left(\mathrm{AGB}_{\mathrm{t}}\right)$ using a wood density value of $0.59 \mathrm{~g}$ $\mathrm{cm}^{-3}$ (Chudnoff, 1984). $\mathrm{AGB}_{\mathrm{t}}$ varied from $18 \mathrm{~kg}$ to 121.90 tons per tree, with an average value of $10.25 \pm 8.07$ tons. The relation between $\mathrm{AGB}_{\mathrm{t}}$ and $\mathrm{SP}_{\mathrm{t}}$ was unimodal to asymptotic (Thomas et al., 2017).

Low-intensity timber extraction, mostly focusing on selected timber species such as Cedrela odorata and Swietenia macrophylla, was prevalent in Brazil nut-rich forests several decades before the concession system was established and logging was formalized by a government decree in 2004 (Rockwell et al., 2017). However, the logging does not seem to have influenced 


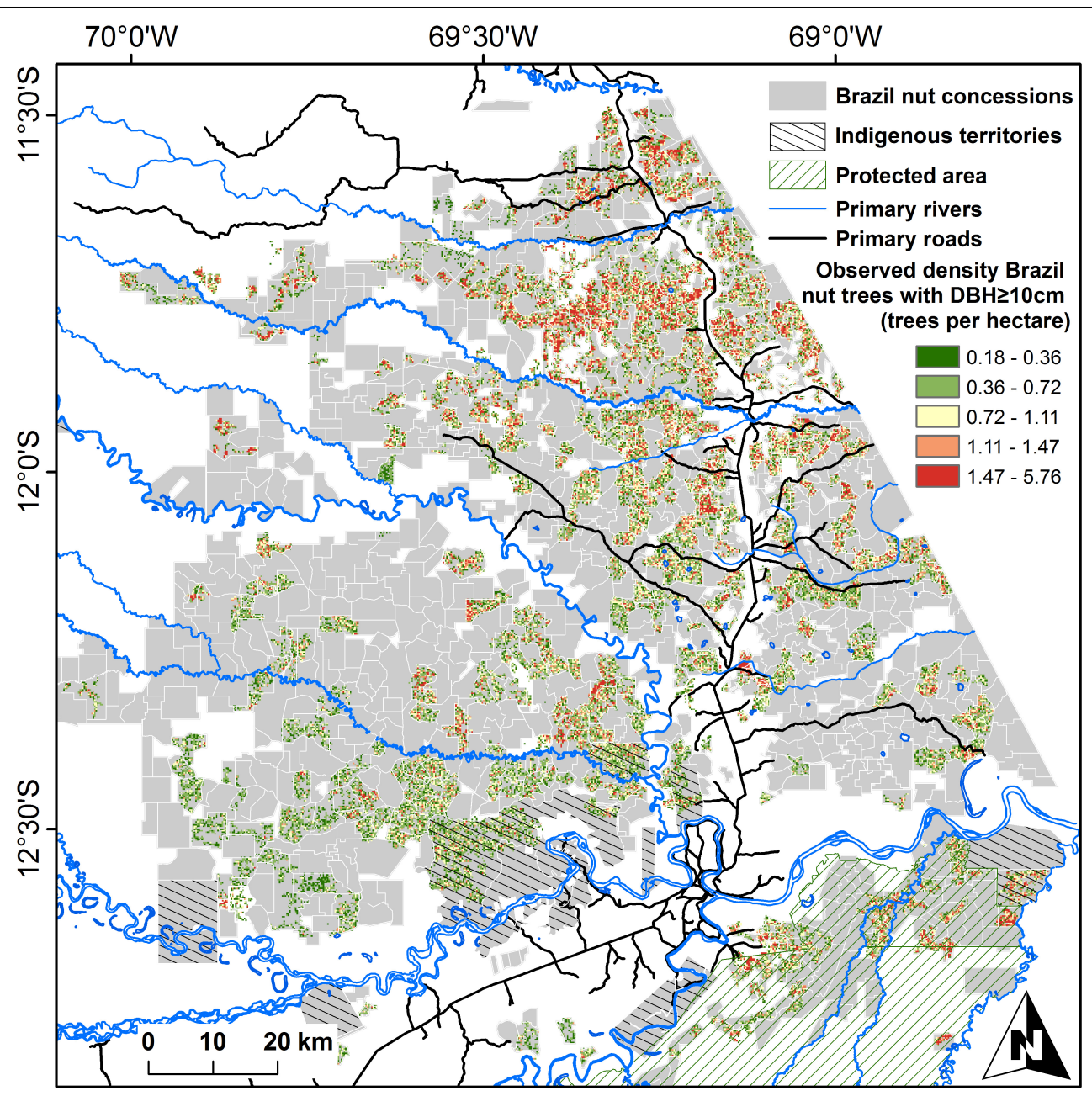

FIGURE 3 | Distribution of Brazil nut concessions in Madre de Dios, Peru. Brazil nut tree densities [diameter at breast height (DBH) $\geq 10 \mathrm{~cm}$ ] in concessions considered in this paper are presented as average numbers of trees per hectare, calculated from projections of single trees on 7.5-arc-second grid cells. Gray areas in sampled concessions had zero densities.

Brazil nut regeneration patterns (Rockwell et al., 2017). This, together with the absence of high-density stands of adult Brazil nuts in the concession system (Thomas et al., 2015; Porcher et al., 2018), suggests that anthropogenic influences on Brazil nut tree density, seed production, and AGB have been minimal.

The environmental variables considered for explaining patterns in tree density, estimated AGB, and seed production were as follows: closeness to rivers and roads (binary variables; see below); all bioclimatic variables extracted from WorldClim climate layers (Hijmans et al., 2005); elevation; slope; terrain ruggedness index; and six major edaphic variables [organic carbon (ORCDRC), $\mathrm{pH}$ in $\mathrm{H}_{2} \mathrm{O}$ (PHIHOX), sand \% (SNDPPT), silt \% (SLTPPT), clay \% (CLYPPT), and bulk density (BLD)] obtained from ISRIC-World Soil Information (Hengl et al., 2014). For the edaphic variables, we calculated a weighted mean across $0-5,5-15,15-30,30-60$, and $60-100 \mathrm{~cm}$ of soil depth values in order to derive a single data value for $0-100 \mathrm{~cm}$. Table 1 gives an overview of the environmental gradients covered by the Brazil nut trees included in our dataset. It shows that while the study area is relatively small, the environmental gradients are wide enough for the purpose of this paper.

\section{Statistical Analyses}

The accuracy and precision of area-based ecosystem service assessments are influenced by the spatial resolution of the analysis, and in the case of Brazil nut unit sizes above 5 ha have been recommended (Thomas et al., 2018). We therefore carried out area-based comparisons at a 7.5-arc-second resolution ( $\sim 5.4$ ha at the equator). We generated a Brazil nut tree density map by projecting all trees on a 7.5 -arc-second raster map, considering only grid cells with $\geq 90 \%$ spatial overlap with the polygons of inventoried concession, resulting in 56,818 grid cells with data and 32,528 grid cells with at least one tree (Figure 3). Cells intersected by roads or rivers were assigned a value of 1 , and other cells a value of 0 .

We used the method of Clark and Evans (1954) to generate maps with custom-made scripts in R (R Core Team, 2015) of 
TABLE 1 | Ranges of considered environmental variables in the study area.

\begin{tabular}{|c|c|c|}
\hline & Min & Max \\
\hline Bio1-Annual temperature $\left({ }^{\circ} \mathrm{C}\right)$ & 24.3 & 25.6 \\
\hline Bio2-Mean diurnal range $\left({ }^{\circ} \mathrm{C}\right)$ & 10.6 & 11.4 \\
\hline Bio3-Isothermality & 66 & 75 \\
\hline Bio4-Temp seasonality & 973 & 1,182 \\
\hline Bio5-Max temp warmest month $\left({ }^{\circ} \mathrm{C}\right)$ & 31.5 & 33.0 \\
\hline Bio6-Min temp coldest month $\left({ }^{\circ} \mathrm{C}\right)$ & 15.2 & 17.6 \\
\hline Bio7-Annual temp range $\left({ }^{\circ} \mathrm{C}\right)$ & 14.2 & 16.9 \\
\hline Bio8-Mean temp wettest quarter $\left({ }^{\circ} \mathrm{C}\right)$ & 25.0 & 26.4 \\
\hline Bio9-Mean temp driest quarter $\left({ }^{\circ} \mathrm{C}\right)$ & 22.6 & 24.0 \\
\hline Bio10-Mean temp warmest quarter $\left({ }^{\circ} \mathrm{C}\right)$ & 25.2 & 26.6 \\
\hline Bio11-Mean temp coldest quarter $\left({ }^{\circ} \mathrm{C}\right)$ & 22.6 & 24.0 \\
\hline Bio12-Annual precipitation (mm) & 1,794 & 3,093 \\
\hline Bio13-Precipitation wettest month (mm) & 246 & 460 \\
\hline Bio14-Precipitation driest month (mm) & 28 & 104 \\
\hline Bio15-Precipitation seasonality & 46 & 56 \\
\hline Bio16-Precipitation of wettest quarter (mm) & 724 & 1,268 \\
\hline Bio17-Precipitation of driest quarter (mm) & 122 & 344 \\
\hline Bio18-Precipitation of warmest quarter (mm) & 462 & 1,150 \\
\hline Bio19-Precipitation of coldest quarter (mm) & 122 & 344 \\
\hline Sand content (\%) & 30.7 & 54.7 \\
\hline Clay content (\%) & 27.7 & 40.6 \\
\hline Silt content (\%) & 14.0 & 31.1 \\
\hline Bulk density $\left(\mathrm{kg} / \mathrm{m}^{3}\right)$ & $1,239.2$ & $1,551.8$ \\
\hline Organic carbon (g/kg) & 4.05 & 31.95 \\
\hline $\mathrm{pH}$ & 4.29 & 5.48 \\
\hline Elevation (m.a.s.l.) & 176 & 408 \\
\hline Slope $\left(^{\circ}\right)$ & 0 & 7.5 \\
\hline TRI & 0.38 & 36.88 \\
\hline
\end{tabular}

the spatial aggregation of Brazil nut trees, whereby a value of 1 indicates random patterns, more than 1 more even spacing patterns, and less than 1 aggregated patterns (Clark and Evans, 1954). We corrected for edge effects by excluding trees that were located closer to a grid cell edge than to their closest neighbor using average nearest neighbor distance calculations per grid cell. Raster maps of estimated AGB and seed production $\left(\mathrm{AGB}_{\mathrm{a}}\right.$ and $\mathrm{SP}_{\mathrm{a}}$ ) were obtained by summing the corresponding $\mathrm{ABG}$ and seed production scores of individual trees per grid cell.

To assess the importance of environmental variables in explaining the variability in the six different response variables $\left(\mathrm{SP}_{\mathrm{t}}, \mathrm{AGB}_{\mathrm{t}}\right.$, tree density and spatial aggregation, and $\mathrm{SP}_{\mathrm{a}}$, and $\mathrm{AGB}_{\mathrm{a}}$ ), we developed random forest models by means of the cforest function in the party package for $\mathrm{R}$ (Strobl et al., 2007) and calculated importance values with the varimp function. Random forest models are not influenced by collinearity of variables, which is the reason why we included all climate and soil variables, in spite of strong correlations between some of them (Supplementary Figures 1-3). We included tree size (height and $\mathrm{DBH}$ ), phytosanitary (presence of broken branches, tumors, vines, holes, exudate, and termites), and conspecific neighborhood variables (distance to nearest conspecific neighbor, spatial aggregation, and tree density) in random forest models of the tree-centric variables (height and $\mathrm{DBH}$ only in the seed production model) to assess their relative importance compared with the environmental variables.

We assessed the nature of the relationship between each of the six response variables and the environmental variables using generalized linear mixed models (GLMMs). We constructed GLMMs with Poisson distribution and log link functions for the density, and tree-centric and area-based seed production models, which were expressed as numbers of trees and multiples of tin cans, respectively. To account for overdispersion in these models, we corrected the standard errors using quasi GLMMs, where the variance is given by the product of the mean and the dispersion parameter. For spatial aggregation and tree-centric and area-based AGB, we constructed GLMMs with a Gaussian distribution. The presence of positive spatial autocorrelation in model residuals (assessed by means autocorrelograms) was effectively accounted for by including the concession where each tree was sampled as a random effect variable. GLMMs were implemented using Penalized Quasi-Likelihood in the MASS package for R (Venables and Ripley, 2002). Considering that different climate variables for different periods throughout the year (cf. Figure 2), in spite of being collinear, may generate different responses in tree-centric and area-based Brazil nut response variables, we retained all variables in the analysis.

\section{RESULTS}

Variable importance scores of random forest models revealed that precipitation variables (Bio12-19) were generally more important predictors of variation in all response variables than temperature (Bio1-11) and soil variables (Figure 4). Of the terrain variables, only elevation was among the 15 most important predictors of all response variables, and the most important for tree density and $\mathrm{SP}_{\mathrm{a}}$ and $\mathrm{AGB}_{\mathrm{a}}$. Of the tree-specific phytosanitary and size variables, only diameter and height were among the most important predictors of $\mathrm{SP}_{\mathrm{t}}$. The suites of key predictors were relatively similar for all response variables, but their order varied considerably across response variables, albeit less so for tree density and $\mathrm{AGB}_{\mathrm{a}}$.

Generalized linear mixed models characterizing the relationships between each of the six response variables and environmental gradients yielded low $R^{2}$ values but allowed for the identification of significant signals of environmental filtering (Supplementary Figures 4-27). Responses to precipitation gradients generally had steeper slopes than the responses to most temperature variables, supporting the finding of the random forest modeling that precipitation variables were generally more important than temperature variables in explaining variation in the response variables. While the collinear temperature variables (Biol and 8-11) showed very similar patterns (in spite of differences in strength of correlations), responses to the collinear precipitation variables (Bio12-14 and 16-19) were much more variable (Table 2).

Tree-centric habitat quality measures $\left(\mathrm{SP}_{t}\right.$ and $\left.\mathrm{AGB}_{\mathrm{t}}\right)$ showed congruent responses to most (but not all) of the environmental variables tested but yielded opposite trends to Brazil nut tree density in about half of the cases, even so when excluding 


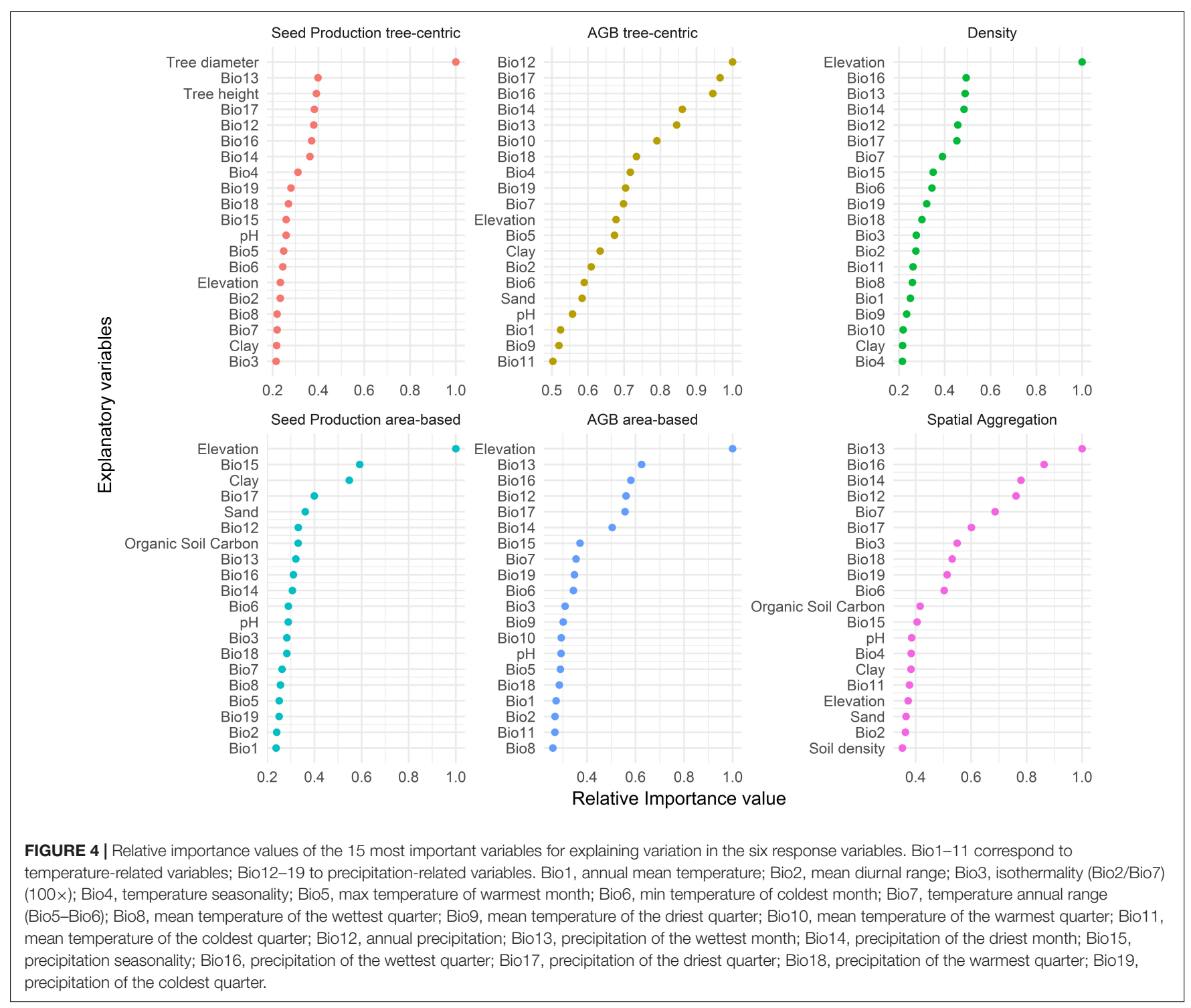

collinear variables with similar responses (Table 2, Figure 5, and Supplementary Figures 4-27). As expected, density and spatial aggregation of Brazil nut trees yielded almost identical responses (Figure 5), suggesting that both are controlled by similar ecological processes. Opposite responses of tree-centric and area-based habitat quality measures to environmental variables (middle left graph Figure 6) resulted in predominantly neutralizing effects for relationships between environmental variables and $\mathrm{SP}_{\mathrm{a}}$ (non-significant relations in eight out of 11 cases; dashed red box Figure 6). By contrast, responses of $\mathrm{AGB}_{\mathrm{a}}$ strongly mirrored those of tree density (10 out of 13 cases; dashed black box Figure 6).

\section{DISCUSSION}

Our objective was to assess the existence of habitat quality differentiation between individuals and stands of Brazil nut trees and to identify the environmental drivers contributing to this differentiation. Our findings show that the environmental gradients we considered generated approximately 50\% congruent and $50 \%$ divergent responses of fitness variables [seed production $\left(\mathrm{SP}_{\mathrm{t}}\right)$ or aboveground biomass $\left.\left(\mathrm{AGB}_{\mathrm{t}}\right)\right]$ on the one hand and tree density on the other. In the case of divergent responses, we expected environmental filters on $\mathrm{SP}_{\mathrm{a}}$ and $\mathrm{AGB}_{\mathrm{a}}$ to mirror those of tree density, but this was only the case for $\mathrm{AGB}_{\mathrm{a}}$. In contrast, relations between environmental variables and $\mathrm{SP}_{\mathrm{a}}$ tended to be predominantly neutralized by the opposite responses of $\mathrm{SP}_{\mathrm{t}}$ and tree density (Figure 7 ). Hence, while we accept our first hypothesis (that the responses of area-based ecosystem service production by the Brazil nut to environmental gradients mirror those of its density) for AGB, we partly reject it for seed production. The trade-offs created by multiple climate and soil gradients between density and fitness of Brazil nut trees on the other hand are in line with our second hypothesis (density and aggregation responses to gradients are governed 
TABLE 2 | Relations between environmental variables and Brazil nut tree fitness variables, densities and spatial aggregation, and tree- and area-based AGB and estimated seed production.

\begin{tabular}{|c|c|c|c|c|c|c|c|}
\hline \multirow[b]{2}{*}{$\begin{array}{l}\text { Corresponding } \\
\text { time period }\end{array}$} & & \multicolumn{2}{|c|}{$\begin{array}{c}\text { Tree-centric habitat quality } \\
\text { measures (fitness) }\end{array}$} & \multirow{2}{*}{$\begin{array}{c}\text { Area-based habitat } \\
\text { quality measure } \\
\text { Tree density }\end{array}$} & \multirow[b]{2}{*}{ Spatial aggregation } & \multicolumn{2}{|c|}{$\begin{array}{c}\text { Area-based } \\
\text { ecosystem services }\end{array}$} \\
\hline & & $\mathbf{S P}_{\mathrm{t}}$ & $\mathrm{AGB}_{\mathrm{t}}$ & & & $\mathrm{SP}_{\mathrm{a}}$ & $\mathrm{AGB}_{\mathrm{a}}$ \\
\hline & - Annual temperature (Bio1)* & $\downarrow \downarrow \downarrow$ & $\downarrow \downarrow \downarrow$ & $\downarrow \downarrow \downarrow$ & $\downarrow \downarrow \downarrow$ & $\downarrow \downarrow \downarrow$ & $\downarrow \downarrow \downarrow$ \\
\hline & - Mean diurnal range (Bio2) & $\uparrow \uparrow \uparrow$ & - & $\uparrow \uparrow \uparrow$ & $\uparrow \uparrow \uparrow$ & $\uparrow \uparrow \uparrow$ & $\uparrow \uparrow \uparrow D$ \\
\hline & • Isothermality (Bio3) & $\uparrow \uparrow \uparrow$ & $\uparrow \uparrow \uparrow$ & $\downarrow \downarrow \downarrow$ & $\downarrow \downarrow \downarrow$ & $-N$ & $\downarrow D$ \\
\hline & • Temp seasonality (Bio4) & $\downarrow \downarrow \downarrow$ & $\downarrow \downarrow$ & $\uparrow \uparrow \uparrow$ & $\uparrow \uparrow \uparrow$ & $-N$ & $-N$ \\
\hline September & - Max temp warmest month (Bio5) & $\downarrow \downarrow \downarrow$ & $\downarrow \downarrow \downarrow$ & $\downarrow \downarrow \downarrow$ & $\uparrow \uparrow$ & $\downarrow \downarrow \downarrow$ & $\downarrow \downarrow \downarrow$ \\
\hline \multirow[t]{2}{*}{ July } & - Min temp coldest month (Bio6) & $\downarrow \downarrow \downarrow$ & $\uparrow \uparrow$ & $\downarrow \downarrow \downarrow$ & $\downarrow \downarrow \downarrow$ & $\downarrow \downarrow \downarrow$ & $\downarrow \downarrow \downarrow D$ \\
\hline & - Annual temp range (Bio7) & - & $\downarrow \downarrow \downarrow$ & $\uparrow \uparrow \uparrow$ & $\uparrow \uparrow \uparrow$ & $\uparrow \uparrow \uparrow D$ & $\uparrow \uparrow \uparrow D$ \\
\hline $\begin{array}{l}\text { December- } \\
\text { February }\end{array}$ & - Mean temp wettest quarter (Bio8)* & $\downarrow \downarrow \downarrow$ & $\downarrow \downarrow \downarrow$ & $\downarrow \downarrow \downarrow$ & $\downarrow \downarrow$ & $\downarrow \downarrow \downarrow$ & $\downarrow \downarrow \downarrow$ \\
\hline June-August & - Mean temp driest quarter (Bio9)* & $\downarrow \downarrow \downarrow$ & $\downarrow$ & $\downarrow \downarrow \downarrow$ & $\downarrow \downarrow \downarrow$ & $\downarrow \downarrow \downarrow$ & $\downarrow \downarrow \downarrow$ \\
\hline $\begin{array}{l}\text { September- } \\
\text { November }\end{array}$ & - Mean temp warmest quarter (Bio10)* & $\downarrow \downarrow \downarrow$ & $\downarrow \downarrow \downarrow$ & $\downarrow \downarrow \downarrow$ & $\downarrow$ & $\downarrow \downarrow \downarrow$ & $\downarrow \downarrow \downarrow$ \\
\hline \multirow[t]{2}{*}{ May-July } & - Mean temp coldest quarter (Bio11)* & $\downarrow \downarrow \downarrow$ & $\downarrow \downarrow$ & $\downarrow \downarrow \downarrow$ & $\downarrow \downarrow \downarrow$ & $\downarrow \downarrow \downarrow$ & $\downarrow \downarrow \downarrow$ \\
\hline & - Annual precipitation (Bio12) & $\uparrow$ & $\uparrow \uparrow \uparrow$ & $\downarrow \downarrow \downarrow$ & $\downarrow \downarrow \downarrow$ & $-N$ & $\downarrow \downarrow \downarrow D$ \\
\hline January & - Precipitation wettest month (Bio13) & $\uparrow \uparrow$ & $\uparrow \uparrow \uparrow$ & $\downarrow \downarrow \downarrow$ & $\downarrow \downarrow \downarrow$ & $-N$ & $\downarrow \downarrow \downarrow D$ \\
\hline \multirow[t]{2}{*}{ July } & - Precipitation driest month (Bio14) & $\uparrow \uparrow \uparrow$ & $\uparrow \uparrow$ & $\downarrow \downarrow \downarrow$ & $\downarrow \downarrow \downarrow$ & $\downarrow D$ & $\downarrow \downarrow \downarrow D$ \\
\hline & - Precipitation seasonality (Bio15) & $\uparrow \uparrow \uparrow$ & $\downarrow$ & $\uparrow \uparrow \uparrow$ & $\uparrow \uparrow \uparrow$ & $\uparrow \uparrow \uparrow$ & $\uparrow \uparrow \uparrow D$ \\
\hline $\begin{array}{l}\text { December- } \\
\text { February }\end{array}$ & - Precipitation of wettest quarter (Bio16)\# & $\uparrow \uparrow$ & $\uparrow \uparrow \uparrow$ & $\downarrow \downarrow \downarrow$ & $\downarrow \downarrow \downarrow$ & $-N$ & $\downarrow \downarrow \downarrow D$ \\
\hline June-August & - Precipitation of driest quarter (Bio17) & $\uparrow \uparrow \uparrow$ & $\uparrow$ & $\downarrow \downarrow \downarrow$ & $\downarrow \downarrow \downarrow$ & $\downarrow D$ & $\downarrow \downarrow \downarrow D$ \\
\hline $\begin{array}{l}\text { September- } \\
\text { November }\end{array}$ & - Precipitation of warmest quarter (Bio18) & - & - & $\downarrow \downarrow \downarrow$ & $\downarrow \downarrow \downarrow$ & $-F$ & $\ddagger D$ \\
\hline \multirow[t]{10}{*}{ May-July } & - Precipitation of coldest quarter (Bio19) & $\uparrow \uparrow \uparrow$ & $\uparrow \uparrow$ & $\downarrow \downarrow \downarrow$ & $\downarrow \downarrow \downarrow$ & $-N$ & $\downarrow D$ \\
\hline & - \%Sand & $\downarrow \downarrow \downarrow$ & - & $\uparrow$ & $\uparrow \uparrow \uparrow$ & $\downarrow \downarrow F$ & $-F$ \\
\hline & • \%Clay & $\uparrow \uparrow$ & - & - & $\downarrow \downarrow \downarrow$ & $\uparrow F$ & - \\
\hline & - \%Silt & $\uparrow \uparrow \uparrow$ & - & - & $\downarrow \downarrow$ & $\uparrow \uparrow \uparrow F$ & - \\
\hline & - Bulk density & $\uparrow$ & - & $\uparrow \uparrow \uparrow$ & $\uparrow \uparrow \uparrow$ & - & $-F$ \\
\hline & - Organic carbon & $\uparrow \uparrow$ & $\uparrow$ & $\downarrow \downarrow \downarrow$ & $\downarrow \downarrow \downarrow$ & $-N$ & $-N$ \\
\hline & $\cdot \mathrm{pH}$ & $\downarrow \downarrow \downarrow$ & $\downarrow \downarrow \downarrow$ & $\uparrow \uparrow \uparrow$ & $\uparrow \uparrow \uparrow$ & $-N$ & $-N$ \\
\hline & - Elevation & $\uparrow \uparrow \uparrow$ & $\uparrow \uparrow \uparrow$ & $\uparrow \uparrow \uparrow$ & $\uparrow \uparrow \uparrow$ & $\uparrow \uparrow \uparrow$ & $\uparrow \uparrow \uparrow$ \\
\hline & - Slope & $\downarrow \downarrow \downarrow$ & $\downarrow \downarrow \downarrow$ & $\downarrow \downarrow \downarrow$ & - & $\downarrow \downarrow \downarrow$ & $\downarrow \downarrow \downarrow$ \\
\hline & • TRI & $\downarrow \downarrow \downarrow$ & $\downarrow \downarrow \downarrow$ & $\downarrow \downarrow \downarrow$ & - & $\downarrow \downarrow \downarrow$ & $\downarrow \downarrow \downarrow$ \\
\hline
\end{tabular}

$\uparrow$ and $\downarrow P \leq 0.1 ; \uparrow$ and $\downarrow P \leq 0.05 ; \uparrow \uparrow$ and $\downarrow \downarrow P \leq 0.01 ; \uparrow \uparrow \uparrow$ and $\downarrow \downarrow \downarrow P \leq 0.001$.

*Colinear temperature variables; " colinear precipitation variables.

$D$ correlation parallels density trend; F correlation follows fitness $\left(A G B_{t}\right.$ or $\left.S P_{t}\right)$ trend; N opposite density and tree-centric trends neutralize each other.

Phenological data are based on the authors' long-term observations of Brazil nut phenology in the study region.

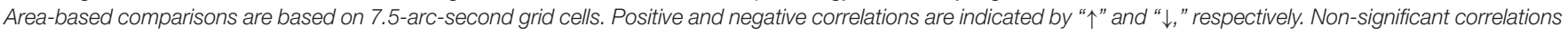
are indicated by "-". For ease of interpretation, correlations for spatial aggregation are the inverse of those obtained based on Clark and Evan's method (randomness).

by expectations under the Janzen-Connell and Herms-Mattson hypotheses, whereas fitness responses are in line with niche preferences and resource requirements of trees across their life cycles). In the following sections, we discuss how our findings are in support of these hypotheses. We conclude with a discussion of implications of our findings and suggest avenues of future research.

\section{Climate-Driven Habitat Quality Differentiation}

Our findings suggest that higher precipitation volumes in different periods of the year positively influence Brazil nut fitness variables but tend to decrease tree density and aggregation. This is in line with the Janzen-Connell hypothesis, which predicts Brazil nut tree recruitment to be lower and less aggregated in more rainy areas due to stronger CNDDD effects associated with increased pest and disease pressure on seedlings and saplings under wetter conditions (Swinfield et al., 2012; Comita et al., 2014; Uriarte et al., 2018). Pest- and disease-related mortality in Brazil nut in the study region is likely to occur during the transition from small $(<50 \mathrm{~cm})$ to large seedlings $(50-150 \mathrm{~cm})$ due to aerial pest and diseases, soil-borne pathogens, or both (Porcher et al., 2018).

While lower precipitation levels were associated with higher Brazil nut density, $\mathrm{AGB}_{\mathrm{t}}$ and $\mathrm{SP}_{\mathrm{t}}$ tended to be lower. Water 

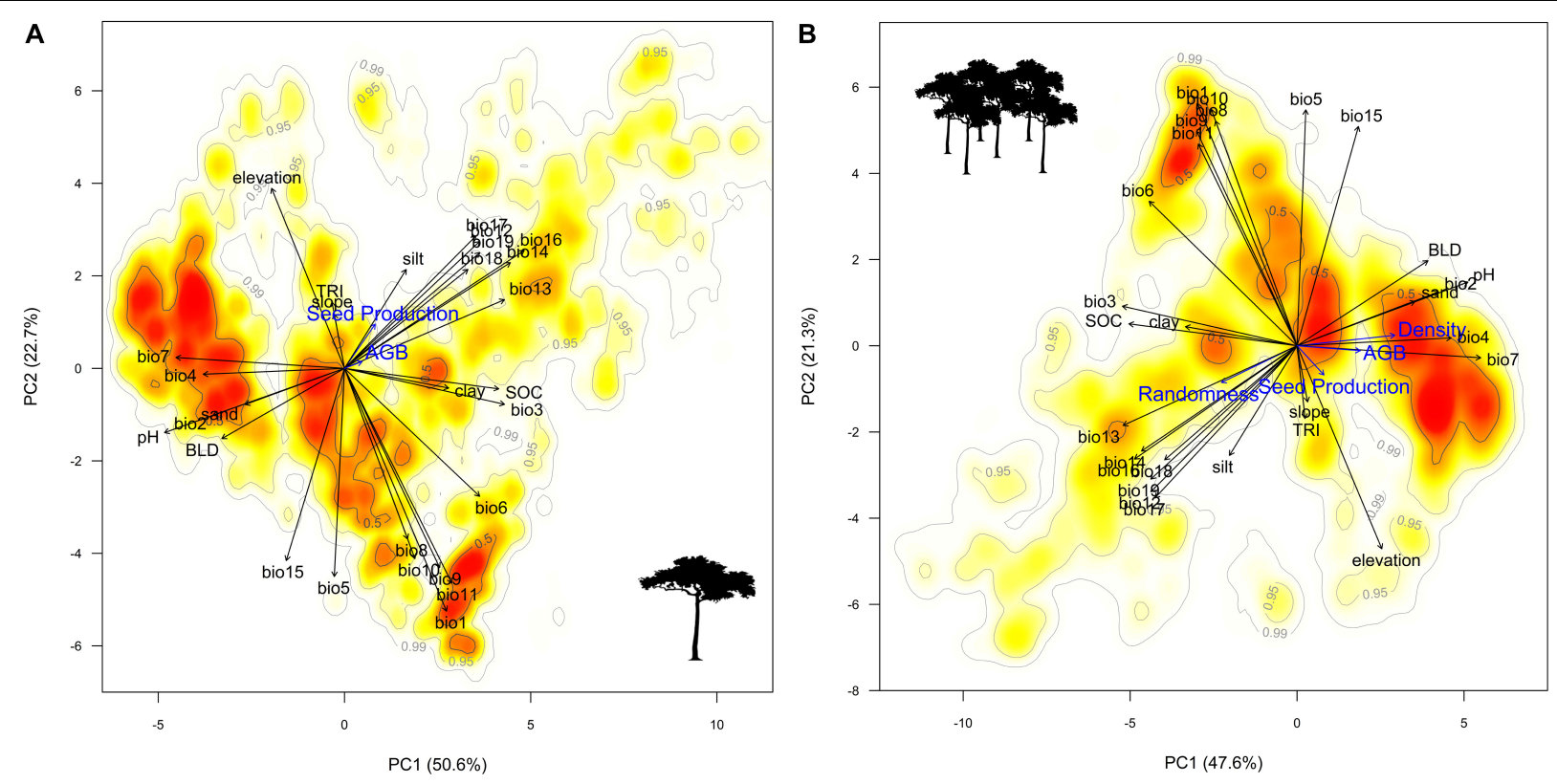

FIGURE 5 | Ordination plots showing the first two axes of principal component analyses of tree-centric Brazil nut variables (A) and area-based Brazil nut variables (B). The color gradient indicates regions of the highest (red) to lowest (white) densities of data points, i.e., individual Brazil nut trees in (A) and 7.5-arc-second grid cells in (B), through use of Kernell density estimations. Please note that randomness is inversely related with spatial aggregation. Arrows of the response variables were doubled (B) to tripled (A) in length to improve interpretation. Bio1, annual mean temperature; Bio2, mean diurnal range; Bio3, isothermality (Bio2/Bio7) (100x); Bio4, temperature seasonality; Bio5, max temperature of the warmest month; Bio6, min temperature of the coldest month; Bio7, temperature annual range (Bio5-Bio6); Bio8, mean temperature of the wettest quarter; Bio9, mean temperature of the driest quarter; Bio10, mean temperature of the warmest quarter; Bio11, mean temperature of the coldest quarter; Bio12, annual precipitation; Bio13, precipitation of the wettest month; Bio14, precipitation of the driest month; Bio15, precipitation seasonality; Bio16, precipitation of the wettest quarter; Bio17, precipitation of the driest quarter; Bio18, precipitation of the warmest quarter; Bio19, precipitation of the coldest quarter.

limitation is increasingly found to constrain tree growth in forests around the world and disproportionately so in the largest trees (Bennett et al., 2015; Babst et al., 2019). Adult Brazil nut trees are canopy emergents and hence likely to be more vulnerable to hydraulic stress and experience higher radiation and evaporative demand because of exposed crowns (Bennett et al., 2015). Rainfall was among the most important variables positively influencing basal area increment and seed production of Brazil nut trees in Acre, Brazil (Kainer et al., 2007; Staudhammer et al., 2013). However, while precipitation during the dry season was strongly related to $\mathrm{SP}_{\mathrm{t}}$ (Supplementary Figure 5 and Kainer et al., 2007), we found it to be only weakly correlated with $\mathrm{AGB}_{\mathrm{t}}$. We suggest that this may be due to this being the period Brazil nut trees shed leaves and hence photosynthetic activity and stem growth slows down, whereas fruit growth is at its midpoint (Figure 2) (Cavalcante, 1991; Schöngart et al., 2015).

Higher air temperatures in different periods of the year tended to negatively influence both tree-centric and area-based Brazil nut variables, which again is in line with expectations. The Janzen-Connell hypothesis predicts that enemy-mediated conspecific effects are amplified under warmer conditions and hence lead to lower conspecific tree density and aggregation (Swinfield et al., 2012; Comita et al., 2014). In line with our findings, Thompson et al. (2010) found that fungus-induced mortality of seedlings of the Amazonian hyperdominant palm Iriartea deltoidea increased with air temperature. On the other hand, the positive effect of temperature on pathogen proliferation only plays within certain temperature ranges, while extreme temperatures have been shown to inhibit growth and spore germination of fungal pathogens (Copes and Hendrix, 2004; Thompson et al., 2010), particularly in combination with low humidity (Talley et al., 2002). This might explain why we found a negative correlation between the spatial aggregation of Brazil nut trees and the maximum temperature of the warmest month, which follows the driest quarter of the year in the study region.

Our results further add support to the growing body of evidence on the negative effects of higher temperatures on the fitness of tropical tree species (Feeley et al., 2007; Way and Oren, 2010; Wagner et al., 2014). Elevated day temperatures may reduce photosynthetic rates in trees due to vapor pressure deficits (the relative dryness of the air), while higher minimum (nighttime) temperatures may inflate respiratory costs (Clark et al., 2013; Allen et al., 2015; Fontes et al., 2018). Negative responses of $S_{t}$ to higher temperatures, particularly during the warmest and wettest quarter, may be because these periods coincide with the periods of flowering and fruit set of Brazil nut (Figure 2) (CorveraGomringer et al., 2010). Exposure to extreme temperatures during the pollination stage, or initial seed or fruit set, is generally expected to reduce yield potential (Redmond et al., 2012; Hatfield and Prueger, 2015). High temperatures have also been found to increase flower and fruit abortion, particularly during droughts (Leite et al., 2007; Pérez-Ramos et al., 2010; Girard et al., 2012; 


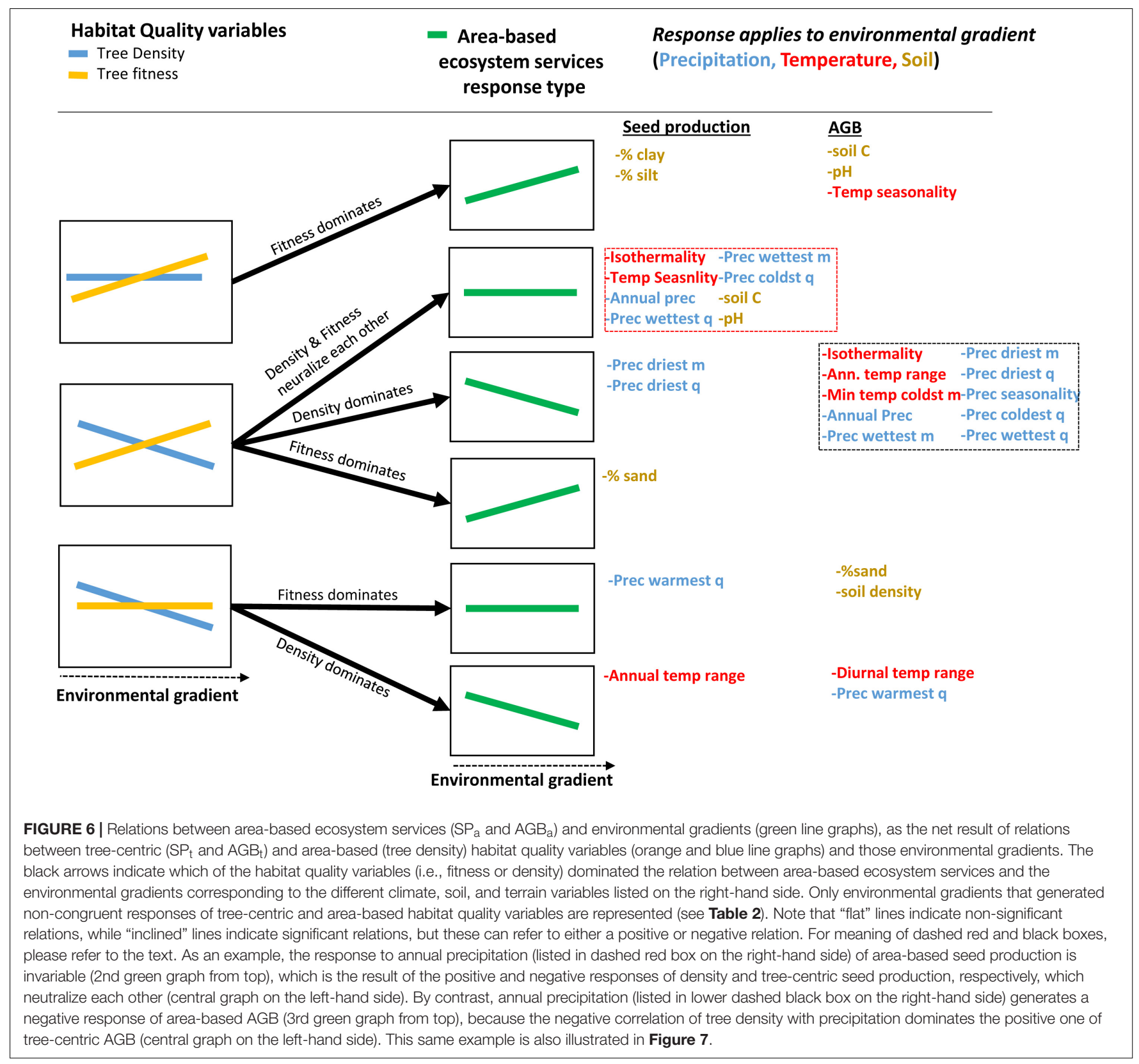

Hatfield and Prueger, 2015). There is anecdotal evidence from our study region, Madre de Dios, that a combination of high temperatures and droughts in 2005 and 2010 led to massive Brazil nut flower abortion (Thomas et al., 2017).

Higher variability in precipitation and temperature regimes on daily and annual bases generated more variable responses in tree-centric and area-based Brazil nut variables. In line with the Janzen-Connell hypothesis that pest- and disease-related mortality of conspecifics is favored not only by wetter and hotter but also by more stable climate conditions, this explains why the highest Brazil nut tree densities and aggregations tended to be located in areas with higher precipitation and temperature seasonality, as well as higher diurnal and annual temperature ranges. The response of fitness variables on the other hand tended to be governed by niche preferences and resource requirements of Brazil nut trees across their life cycles. $\mathrm{AGB}_{\mathrm{t}}$ was positively influenced by more stable and moderate precipitation and temperature regimes, i.e., lower variability and extremes on seasonal and yearly bases. Higher precipitation seasonality in the tropics has been found to limit leaf carbon assimilation and wood production of trees (Saatchi et al., 2007; Wagner et al., 2016), which in the case of Brazil nut might translate in lower $\mathrm{AGB}_{\mathrm{t}}$. Both colder temperatures during the coldest month of the year and higher temperatures during the warmest periods of the year were associated with lower $\mathrm{AGB}_{\mathrm{t}}$. The positive correlation between $\mathrm{AGB}_{\mathrm{t}}$ and the minimum temperature of the coldest month was unexpected but could be related to acclimatization of nighttime respiration in response to mean growth temperature 


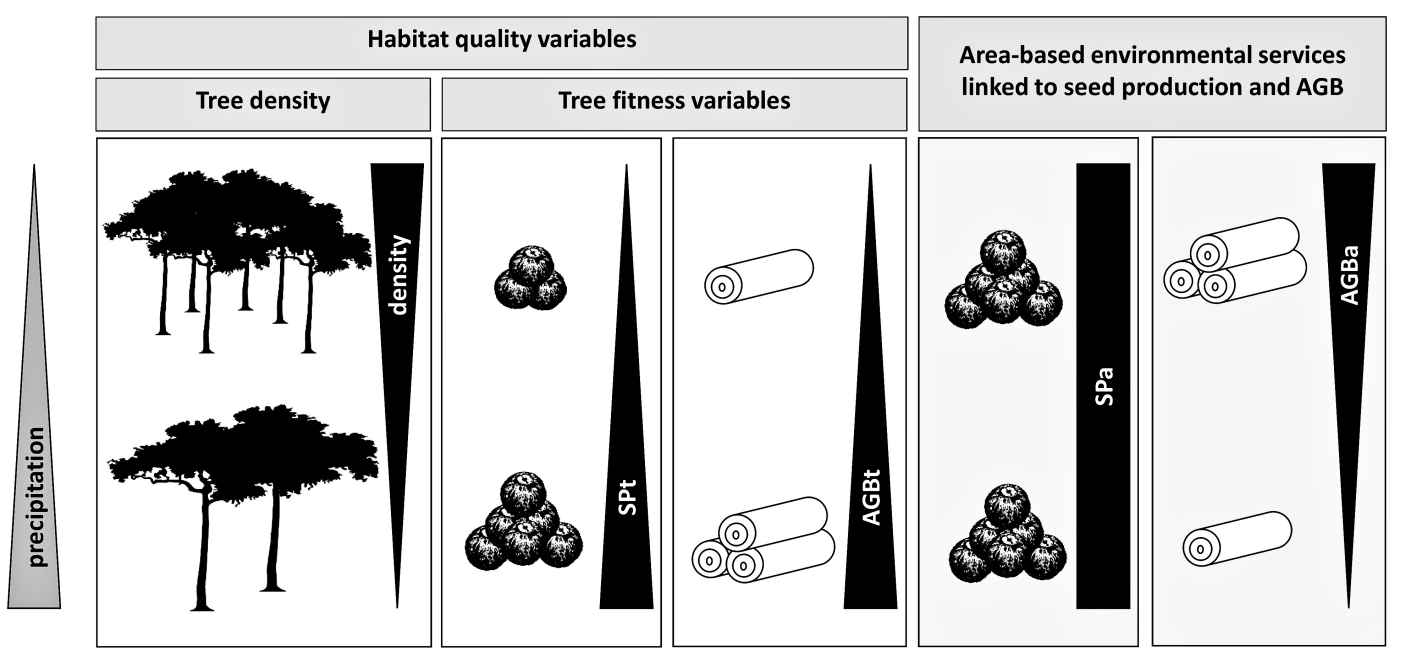

FIGURE 7 | Graphical illustration of how different habitat quality variables and area-based ecosystem services, linked to seed production and AGB of Brazil nut, respond to a precipitation gradient. The positive and negative correlations with precipitation of $\mathrm{SP}_{\mathrm{t}}$ and tree density, respectively, neutralize one another, resulting in invariable $\mathrm{SP}_{\mathrm{a}}$ regardless of precipitation levels. By contrast, the negative correlation of tree density with precipitation dominates the positive one of $\mathrm{AGB}_{\mathrm{t}}$, resulting in a negative correlation of $A G B_{a}$.

(Cheesman and Winter, 2013; Slot et al., 2014). Consistent with this, in a pan-tropical meta-analysis, Wagner et al. (2014) found minimal temperatures to be positively, albeit weakly, correlated with tree growth.

$\mathrm{SP}_{\mathrm{t}}$ showed a more complex relation with temporal climate variability. Similar to $\mathrm{AGB}_{\mathrm{t}}$, it responded positively to lower temperature seasonality and lower maximum temperatures during the warmest periods of the year but negatively to lower precipitation seasonality, which is in line with Müller's (1981) argument that the Brazil nut requires 2-5 months with reduced rainfall for good fruit production. On the other hand, our finding that $\mathrm{SP}_{\mathrm{t}}$ tended to be higher in areas with lower minimum temperatures of the coldest month and higher mean daily temperature ranges suggests that lower night temperatures favor fecundity, possibly in a similar manner as chilling requirements for flowering in temperate fruit trees (Guo et al., 2014).

\section{Soil-Driven Habitat Quality Differentiation}

Our findings further suggest that also soil variables can generate habitat quality differentiation. Soils with lower fertility or less favorable rooting conditions tended to be associated with higher Brazil nut tree density and aggregation, in line with the Herms-Mattson hypothesis, but lower fitness variables, in line with the species' niche preferences and resources requirements. According to the Herms-Mattson hypothesis, infertile soils or unfavorable rooting conditions tend to favor greater allocation to anti-herbivore defenses (secondary metabolites) in trees, which leads to lower rates of pest- and disease-related mortality, hence favoring higher conspecific densities (Givnish, 1999). This hypothesis was experimentally validated by Fine et al. (2006) in the Peruvian Amazon. Accordingly, we found Brazil nut density and aggregation to correlate negatively with soil organic carbon content, which is an indicator of soil fertility, supporting experimental findings from temperate forest that the strength of CNDDD recruitment of seedlings and saplings increased with soil resource availability (LaManna et al., 2016). Similarly, the positive correlation between soil $\mathrm{pH}$ and Brazil nut density and aggregation might be the consequence of the inverse correlation between $\mathrm{pH}$ and organic soil carbon in the study region (Supplementary Figure 3). However, at low $\mathrm{pH}$, elevated levels of certain elements such as aluminum and manganese can reach toxic levels, which may be more difficult to cope with for seedlings and saplings than for adult trees (Delhaize and Ryan, 1995; Melakeberhan et al., 1995). Soils in the study area are known to have an elevated aluminum content (Quesada et al., 2011). In line with the Herms-Mattson hypothesis (Givnish, 1999), Brazil nut tree density and aggregation also correlated positively with the bulk density of the fine earth fraction, which is an indicator of how well plant roots are able to extend into the soil. The highest densities in our dataset occurred in areas with values $>1.35 \mathrm{~g} / \mathrm{cm}^{3}$ above which inhibition of root growth may start (Quesada et al., 2012).

By contrast, more fertile soil conditions tended to increase $\mathrm{SP}_{\mathrm{t}}$ and $\mathrm{AGB}_{\mathrm{t}}$, corroborating field research in Acre, Brazil. Staudhammer et al. (2013) documented a positive relation between soil carbon and basal area increment of Brazil nut trees, while CEC, being collinear with soil carbon, was found to positively influence fruit production of Brazil nut trees in the same study area (Kainer et al., 2007). The strong negative correlations we found between soil $\mathrm{pH}$ and $\mathrm{SP}_{\mathrm{t}}$ and $\mathrm{AGB}_{\mathrm{t}}$ might therefore be a reflection of the strong inverse correlation between $\mathrm{pH}$ and soil organic carbon in the study area (Supplementary Figure 3), although other factors may be important too. For example, more acidic soils in the Amazon have been found to contain higher soil calcium ion concentrations (Laurance et al., 1999), which in turn correlated positively 
with diameter increment of adult Brazil nut trees in Acre (Staudhammer et al., 2013). Similarly, the positive influence on $\mathrm{SP}_{\mathrm{t}}$ by the clay and silt fraction of soils and the negative influence of the sand fraction might be an expression of the positive correlation between clay and silt content and soil organic carbon in the research area (Supplementary Figure 3).

Topographical variables such as elevation, slope, or landscape heterogeneity may influence variation in soil chemistry, hydrology, and microclimate, thus driving niche partitioning and environmental filtering of tree species in tropical forests (Douda et al., 2012; Brown et al., 2013; Jucker et al., 2018; Zuleta et al., 2018; Mutuku and Kenfack, 2019). However, we did not find evidence for topography causing habitat quality differentiation in the Brazil nut. Brazil nut prefers well-drained terra firme soils (Mori and Prance, 1990), which explains why $\mathrm{SP}_{t}$ and $\mathrm{AGB}_{\mathrm{t}}$ increased with elevation. Negative correlations with terrain slope and heterogeneity (TRI) might on the other hand be related to decreasing availability of water and nutrients (Paoli et al., 2008), or the lower likelihood of large-sized Brazil nut trees to establish on hilly terrains. Topographic heterogeneity has been found to positively correlate with tree species richness (Kubota et al., 2004; Douda et al., 2012; Rodrigues et al., 2019). In less topographically heterogeneous forests, one would therefore expect higher abundances of at least some species, which could explain why we found higher Brazil nut tree densities on flatter terrain. Accordingly, Rodrigues et al. (2019) found not only lower diversity in less topographically heterogeneous Brazilian Atlantic forest but also a higher abundance of hyperdominant tree species.

\section{Avenues for Future Research}

While further research is needed to test the validity of the mechanisms underlying the trade-offs between tree-centric and area-based habitat quality variables and quantify the variation in their strength across environmental gradients, previous work (Thomas et al., 2018) has shown that $\mathrm{SP}_{t}$ and $\mathrm{AGB}_{\mathrm{t}}$ are conditioned by CNDDD effects. Environmental controls on tree density are therefore likely to indirectly influence measures of individual tree fitness. An interesting area for future research may be unraveling how the variable strength of CNDDD across environmental gradients leads to divergent responses of tree density and fitness variables.

Environmental variables that generate congruent responses of $\mathrm{SP}_{t}$ or $\mathrm{AGB}_{\mathrm{t}}$ on the one hand and density on the other can be expected to weaken CNDDD of $\mathrm{SP}_{t}$ and $\mathrm{AGB}_{t}$, whereas environmental conditions that foster opposite responses are either expected to promote the strength of CNDDD or have no effect. For example, precipitation correlated positively with $\mathrm{SP}_{\mathrm{t}}$ and $\mathrm{AGB}_{\mathrm{t}}$ and negatively with tree density (Figure 7 ). At the same time, both tree-centric variables also correlated negatively with tree density (Thomas et al., 2018). Hence, in areas with lower precipitation, $\mathrm{SP}_{\mathrm{t}}$ and $\mathrm{AGB}_{\mathrm{t}}$ on average tended to be at the lower end while tree density tended to be at the higher end of the observed spectrum, which might further lower $\mathrm{SP}_{\mathrm{t}}$ and $\mathrm{AGB}_{\mathrm{t}}$ through CNDDD. In this example, precipitation would be considered an environmental variable strengthening CNDDD effects on $\mathrm{SP}_{t}$ and $\mathrm{AGB}_{t}$, analogous with comparable findings for CNDDD effects on recruitment (Comita et al., 2014;
LaManna et al., 2016). Further research at a finer spatial scale is needed to test the validity of this hypothesis.

\section{CONCLUSION}

We found that environmental filters generate trade-offs between tree-centric (fitness) and area-based (density) habitat quality indicators of Brazil nut, which are translated into divergent responses to multiple environmental gradients of area-based ecosystem services related to seed production and AGB. The fact that even within our relatively small study region environmental gradients were pronounced enough to cause these trade-offs suggests that even stronger trends might be detected across the entire species range.

Our finding that higher temperatures tended to affect all habitat quality variables of the Brazil nut negatively, while the influence of precipitation was more variable, but also more important, suggests that climate change is expected to impact the provision of ecosystem services. It is clear that multivariate modeling approaches are needed to obtain a comprehensive understanding of the nature of expected changes in ecosystem service provision by this giant of the Amazon and associated impacts on local livelihoods under climate change.

\section{DATA AVAILABILITY STATEMENT}

Publicly available datasets generated for this study. This data can be found here: https://doi.org/10.1371/journal.pone.0183743. s001.

\section{AUTHOR CONTRIBUTIONS}

ET designed the study, performed data curation and statistical analyses, and prepared the first draft of the manuscript. MJ, FC-A, LW, RC-G, RA, SB, MV-R, and BL contributed to revisions of the manuscript. All authors contributed to the article and approved the submitted version.

\section{FUNDING}

This research was supported by CGIAR Fund Donors, through the CGIAR Research Program on Forests Trees and Agroforestry.

\section{ACKNOWLEDGMENTS}

We are grateful to Carlos Bouroncle, Jheyson Valdivia, and Carolina Alcazar for help with data collection and data curation.

\section{SUPPLEMENTARY MATERIAL}

The Supplementary Material for this article can be found online at: https://www.frontiersin.org/articles/10.3389/fpls.2021. 621064/full\#supplementary-material 


\section{REFERENCES}

Alfaro-Sánchez, R., Muller-Landau, H. C., Wright, S. J., and Camarero, J. J. (2017). Growth and reproduction respond differently to climate in three Neotropical tree species. Oecologia 184, 531-541. doi: 10.1007/s00442-017-3879-3873

Allen, C. D., Breshears, D. D., and McDowell, N. G. (2015). On underestimation of global vulnerability to tree mortality and forest die-off from hotter drought in the Anthropocene. Ecosphere 6, 1-55. doi: 10.1890/ES15-00203.1

Alvarez-Buylla, E. R. (1994). Density dependence and patch dynamics in tropical rain forests: matrix models and applications to a tree species. Am. Nat. 143, 155-191. doi: 10.1086/285599

Babst, F., Bouriaud, O., Poulter, B., Trouet, V., Girardin, M. P., and Frank, D. C. (2019). Twentieth century redistribution in climatic drivers of global tree growth. Sci. $A d v$. 5:eaat4313. doi: 10.1126/sciadv.aat4313

Bachelot, B., Uríarte, M., Thompson, J., and Zimmerman, J. K. (2016). The advantage of the extremes: tree seedlings at intermediate abundance in a tropical forest have the highest richness of above-ground enemies and suffer the most damage. J. Ecol. 104, 90-103. doi: 10.1111/1365-2745.12488

Bean, W. T., Prugh, L. R., Stafford, R., Butterfield, H. S., Westphal, M., and Brashares, J. S. (2014). Species distribution models of an endangered rodent offer conflicting measures of habitat quality at multiple scales. J. Appl. Ecol. 51, 1116-1125. doi: 10.1111/1365-2664.12281

Bennett, A. C., McDowell, N. G., Allen, C. D., and Anderson-Teixeira, K. J. (2015). Larger trees suffer most during drought in forests worldwide. Nat. Plants 1:15139. doi: $10.1038 /$ nplants.2015.139

Bradshaw, C. J. A., and McMahon, C. R. (2008). "Fecundity," in Population Dynamics, eds S. E. Jørgensen and B. D. Fath (Oxford: University of Oxford), 1535-1543. doi: 10.1007/s101440050036

Brienen, R. J. W., Phillips, O. L., Feldpausch, T. R., Gloor, E., Baker, T. R., Lloyd, J., et al. (2015). Long-term decline of the Amazon carbon sink. Nature 519, 344-348. doi: 10.1038/nature14283

Brown, C., Burslem, D. F. R. P., Illian, J. B., Bao, L., Brockelman, W., Cao, M., et al. (2013). Multispecies coexistence of trees in tropical forests: spatial signals of topographic niche differentiation increase with environmental heterogeneity. Proc. R. Soc. B Biol. Sci. 280:20130502. doi: 10.1098/rspb.2013.0502

Cardinale, B. J., Matulich, K. L., Hooper, D. U., Byrnes, J. E., Duffy, E., Gamfeldt, L., et al. (2011). The functional role of producer diversity in ecosystems. Am. J. Bot. 98, 572-592. doi: 10.3732/ajb.1000364

Cavalcante, P. (1991). Frutas Comestiveis da Amazonia (Edible Fruits of the Amazon). Belem: Museu Goeldi.

Chave, J., Réjou-Méchain, M., Búrquez, A., Chidumayo, E., Colgan, M. S., Delitti, W. B. C., et al. (2014). Improved allometric models to estimate the aboveground biomass of tropical trees. Glob. Chang. Biol. 20, 3177-3190. doi: 10.1111/gcb. 12629

Cheesman, A. W., and Winter, K. (2013). Elevated night-time temperatures increase growth in seedlings of two tropical pioneer tree species. New Phytol. 197, 1185-1192. doi: 10.1111/nph.12098

Chudnoff, M. (1984). Tropical Timbers of the World. Washington, DC: USDA Forest Service.

Clark, D. A., Clark, D. B., and Oberbauer, S. F. (2013). Field-quantified responses of tropical rainforest aboveground productivity to increasing $\mathrm{CO} 2$ and climatic stress, 1997-2009. J. Geophys. Res. Biogeosci. 118, 783-794. doi: 10.1002/jgrg. 20067

Clark, D. B., Clark, D. A., and Oberbauer, S. F. (2010). Annual wood production in a tropical rain forest in NE Costa Rica linked to climatic variation but not to increasing $\mathrm{CO} 2$ Annual wood production in a tropical rain forest in NE Costa Rica linked to climatic variation but not to. Glob. Chang. Biol. 16, 747-759. doi: 10.1111/j.1365-2486.2009.02004.x

Clark, J. S., Iverson, L., Woodall, C. W., Allen, C. D., Bell, D. M., Bragg, D. C., et al. (2016). The impacts of increasing drought on forest dynamics, structure, and biodiversity in the United States. Glob. Chang. Biol. 22, 2329-2352. doi: $10.1111 /$ gcb. 13160

Clark, P. J., and Evans, F. C. (1954). Distance to nearest neighbor as a measure of spatial relationships in populations. Ecology 35, 445-453. doi: 10.2307/1931034

Comita, L. S., Muller-landau, H. C., Hubbell, S., and Angeles, L. (2010). Asymmetric density dependence shapes species abundances in a tropical tree community. Science 329, 330-332. doi: 10.1126/science.1190772
Comita, L. S., Queenborough, S. A., Murphy, S. J., Eck, J. L., Xu, K., Krishnadas, M., et al. (2014). Testing predictions of the Janzen-Connell hypothesis: a meta-analysis of experimental evidence for distance- and density-dependent seed and seedling survival. J. Ecol. 102, 845-856. doi: 10.1111/1365-2745. 12232

Connell, J. H. (1971). "On the role of natural enemies in preventing competitive exclusion in some marine animals and in rain forest trees," in Dynamics of Populations, eds P. J. den Boer and G. R. Gradwell (Wageningen: Centre for Agricultural Publishing and Documentation), 298-313.

Copes, W. E., and Hendrix, F. F. (2004). Effect of temperature on sporulation of Botryosphaeria dothidea, B. obtusa, and B. rhodina. Plant Dis. 88, 292-296. doi: 10.1094/PDIS.2004.88.3.292

Corvera-Gomringer, R., del Castillo, Torres, D., Suri Palomino, W., Cusi Auca, E., and Canal Zamora, A. (2010). La castaña Amazonica (Bertholletia excelsa): manual de cultivo.

de Wadt, L. H. O., Faustino, C. L., Staudhammer, C. L., Kainer, K. A., and Evangelista, J. S. (2018). Primary and secondary dispersal of Bertholletia excelsa: implications for sustainable harvests. For. Ecol. Manag. 41, 98-105. doi: 10. 1016/j.foreco.2018.02.014

Delhaize, E., and Ryan, P. R. (1995). Aluminum toxicity and tolerance in plants. Plant Physiol. 107, 315-321. doi: 10.1104/pp.107.2.315

Douda, J., Doudová-Kochánková, J., Boublík, K., and Drašnarová, A. (2012). Plant species coexistence at local scale in temperate swamp forest: test of habitat heterogeneity hypothesis. Oecologia 169, 523-534. doi: 10.1007/s00442-0112211-x

Fauset, S., Johnson, M. O., Gloor, M., Baker, T. R., Monteagudo, M. A., Brienen, R. J., et al. (2015). Hyperdominance in Amazonian forest carbon cycling. Nat. Commun. 6:6857. doi: 10.1038/ncomms7857

Feeley, K. J., Joseph Wright, S., Nur Supardi, M. N., Kassim, A. R., and Davies, S. J. (2007). Decelerating growth in tropical forest trees. Ecol. Lett. 10, 461-469. doi: $10.1111 /$ j.1461-0248.2007.01033.x

Fine, P. V. A., Miller, Z. J., Mesones, I., Irazuzta, S., Appel, H. M., Stevens, M. H. H., et al. (2006). The growth-defense trade-off and habitat specialization by plants in Amazonian forests. Ecology 87, S150-S162. doi: 10.1890/0012-9658200687

Fontes, C. G., Dawson, T. E., Jardine, K., McDowell, N., Gimenez, B. O., Anderegg, L., et al. (2018). Dry and hot: the hydraulic consequences of a climate change-type drought for Amazonian trees. Philos. Trans. R. Soc. B Biol. Sci. 373:20180209. doi: 10.1098/rstb.2018.0209

Gaston, K. J., Cox, D. T. C., Canavelli, S. B., García, D., Hughes, B., Maas, B., et al. (2018). Population abundance and ecosystem service provision: the case of birds. Bioscience 68, 264-272. doi: 10.1093/biosci/biy005

Girard, F., Vennetier, M., Guibal, F., Corona, C., Ouarmim, S., and Herrero, A. (2012). Pinus halepensis mill. crown development and fruiting declined with repeated drought in Mediterranean France. Eur. J. For. Res. 131, 919-931. doi: 10.1007/s10342-011-0565-566

Givnish, T. J. (1999). On the causes of gradients in tropical tree diversity. J. Ecol. 87, 193-210. doi: 10.1046/j.1365-2745.1999.00333.x

Guo, L., Dai, J., Ranjitkar, S., Yu, H., Xu, J., and Luedeling, E. (2014). Chilling and heat requirements for flowering in temperate fruit trees. Int. J. Biometeorol. 58, 1195-1206. doi: 10.1007/s00484-013-0714-713

Gutiérrez, D., Harcourt, J., Díez, S. B., Gutiérrez Illán, J., and Wilson, R. J. (2013). Models of presence-absence estimate abundance as well as (or even better than) models of abundance: the case of the butterfly Parnassius apollo. Landsc. Ecol. 28, 401-413. doi: 10.1007/s10980-013-9847-9843

Harms, K. E., Wright, S. J., Calderón, O., Hernández, A., and Herre, E. A. (2000). Pervasive density-dependent recruitment enhances seedling diversity in a tropical forest. Nature 404, 493-495. doi: 10.1038/35006630

Hatfield, J. L., and Prueger, J. H. (2015). Temperature extremes: effect on plant growth and development. Weather Clim. Extrem. 10, 4-10. doi: 10.1016/j.wace. 2015.08.001

Haugaasen, J. M. T., Haugaasen, T., Peres, C. A., Gribel, R., and Wegge, P. (2010). Seed dispersal of the Brazil nut tree (Bertholletia excelsa) by scatter-hoarding rodents in a central Amazonian forest. J. Trop. Ecol. 26, 251-262. doi: 10.1017/ S0266467410000027

He, F., and Duncan, R. P. (2000). Density-dependent effects on tree survival in an old-growth Douglas fir forest. J. Ecol. 88, 676-688. doi: 10.1046/j.1365-2745. 2000.00482.x 
Hengl, T., de Jesus, J. M., MacMillan, R. A., Batjes, N. H., Heuvelink, G. B. M., Ribeiro, E., et al. (2014). SoilGrids $1 \mathrm{~km}$ - global soil information based on automated mapping. PLoS One 9:e105992. doi: 10.1371/journal.pone.0105992

Herms, D. A., and Mattson, W. J. (1992). The dilemma of plants: to grow or defend. Q. Rev. Biol. 67, 283-335. doi: 10.1086/417659

Hijmans, R. J., Cameron, S. E., Parra, J. L., Jones, P. G., and Jarvis, A. (2005). Very high resolution interpolated climate surfaces for global land areas. Int. J. Climatol. 25, 1965-1978. doi: 10.1002/joc.1276

Hubbell, S. P., Ahumada, J. A., Condit, R., and Foster, R. B. (2001). Local neighborhood effects on long-term survival of individual trees in a neotropical forest. Ecol. Res. 16, 859-875. doi: 10.1046/j.1440-1703.2001.00445.x

Jansen, M., Zuidema, P. A., Anten, N. P. R., and Martínez-Ramos, M. (2012). Strong persistent growth differences govern individual performance and population dynamics in a tropical forest understorey palm. J. Ecol. 100, 12241232. doi: 10.1111/j.1365-2745.2012.02001.x

Janzen, D. H. (1970). Herbivores and the number of tree species in tropical forests. Am. Nat. 104, 501-528. doi: 10.1086/282687

Johnson, M. D. (2007). Measuring habitat quality: a review. Condor 109, 489-504. doi: $10.1650 / 8347.1$

Jones, F. A., and Comita, L. S. (2008). Neighbourhood density and genetic relatedness interact to determine fruit set and abortion rates in a continuous tropical tree population. Proc. R. Soc. B 275, 2759-2767. doi: 10.1098/rspb.2008. 0894

Jucker, T., Bongalov, B., Burslem, D. F. R. P., Nilus, R., Dalponte, M., Lewis, S. L., et al. (2018). Topography shapes the structure, composition and function of tropical forest landscapes. Ecol. Lett. 21, 989-1000. doi: 10.1111/ele.12964

Kainer, K., Wadt, L., and Staudhammer, C. (2007). Explaining variation in Brazil nut fruit production. For. Ecol. Manag. 250, 244-255. doi: 10.1016/j.foreco. 2007.05.024

Kubota, Y., Murata, H., and Kikuzawa, K. (2004). Effects of topographic heterogeneity on tree species richness and stand dynamics in a subtropical forest in Okinawa Island, southern Japan. J. Ecol. 92, 230-240. doi: 10.1111/j. 0022-0477.2004.00875.x

LaManna, J. A., Mangan, S. A., Alonso, A., Bourg, N. A., Brockelman, W. Y., Bunyavejchewin, S., et al. (2017). Plant diversity increases with the strength of negative density dependence at the global scale. Science 356, 1389-1392. doi: 10.1126/science.aam5678

LaManna, J. A., Walton, M. L., Turner, B. L., and Myers, J. A. (2016). Negative density dependence is stronger in resource-rich environments and diversifies communities when stronger for common but not rare species. Ecol. Lett. 19, 657-667. doi: 10.1111/ele.12603

Laurance, W. F., Fearnside, P. M., Laurance, S. G., Delamonica, P., Lovejoy, T. E., Rankin-De Merona, J. M., et al. (1999). Relationship between soils and Amazon forest biomass: a landscape-scale study. For. Ecol. Manag. 118, 127-138. doi: 10.1016/S0378-1127(98)00494-490

Leite, R. J., Petri, J. L., Zhongfu, S., Wang, Y., Szabo, Z., Soltesz, M., et al. (2007). Fruit drop: the role of inner agents and environmental factors in the drop of flowers and fruits. Int. J. Hortic. Sci. 13, 13-23. doi: 10.31421/IJHS/13/3/741

Liang, J., Crowther, T. W., Picard, N., Wiser, S., Zhou, M., Alberti, G., et al. (2016). Positive biodiversity-productivity relationship predominant in global forests. Science 354:aaf8957. doi: 10.1126/science.aaf8957

Mangan, S. A., Schnitzer, S. A., Herre, E. A., Mack, K. M. L., Valencia, M. C., Sanchez, E. I., et al. (2010). Negative plant-soil feedback predicts tree-species relative abundance in a tropical forest. Nature 466, 752-755. doi: 10.1038/ nature 09273

Melakeberhan, H., Jones, A. L., Hanson, E., and Bird, G. W. (1995). Effect of low soil $\mathrm{pH}$ on Aluminium availability and on mortality of cherry seedlings. Plant Dis. 79, 886-892. doi: 10.1094/pd-79-0886

Mori, S. A., and Prance, G. T. (1990). Taxonomy, ecology, and economic botany of the Brazil nut. Adv. Econ. Bot. 8, 130-150.

Müller, C. H. (1981). Castanha-do-brasil: Estudos Agronômicos. Brazil: Belém.

Mutuku, P., and Kenfack, D. (2019). Effect of local topographic heterogeneity on tree species assembly in an Acacia-dominated African Savanna. J. Trop. Ecol. 35, 46-56. doi: 10.1017/s0266467419000014

Oliver, T. H., Gillings, S., Girardello, M., Rapacciuolo, G., Brereton, T. M., Siriwardena, G. M., et al. (2012). Population density but not stability can be predicted from species distribution models. J. Appl. Ecol. 49, 581-590. doi: 10.1111/j.1365-2664.2012.02138.x
Paoli, G. D., Curran, L. M., and Slik, J. W. F. (2008). Soil nutrients affect spatial patterns of aboveground biomass and emergent tree density in southwestern Borneo. Oecologia 155, 287-299. doi: 10.1007/s00442-007-0906-909

Pérez-Ramos, I. M., Ourcival, J. M., Limousin, J. M., and Rambal, S. (2010). Mast seeding under increasing drought: results from a long-term data seat and from a rainfall exclusion experiment. Ecology 91, 3057-3068. doi: 10.1890/09-2313.1

Pimm, S. L., Jones, H. L., and Diamond, J. (1988). On the risk of extinction. Am. Nat. 132, 757-785.

Poorter, L., van der Sande, M. T., Thompson, J., Arets, E. J. M. M., Alarcón, A., Álvarez-Sánchez, J., et al. (2015). Diversity enhances carbon storage in tropical forests. Glob. Ecol. Biogeogr. 24, 1314-1328. doi: 10.1111/geb.12364

Porcher, V., Thomas, E., Corvera Gomringer, R., and Bardales Lozano, R. (2018). Fire- and distance-dependent recruitment of the Brazil nut in the Peruvian Amazon. For. Ecol. Manag. 427, 52-59. doi: 10.1016/j.foreco.2018.05.052

Quesada, C., Phillips, O. L., Schwarz, M., Czimczik, C. I., Baker, T. R., Patiño, S., et al. (2012). Basin-wide variations in Amazon forest structure and function are mediated by both soils and climate. Biogeosciences 9, 2203-2246. doi: 10.5194/ bg-9-2203-2012

Quesada, C. A., Lloyd, J., Anderson, L. O., Fyllas, N. M., Schwarz, M., and Czimczik, C. I. (2011). Soils of Amazonia with particular reference to the RAINFOR sites. Biogeosciences 8, 1415-1440. doi: 10.5194/bg-8-1415-2011

R Core Team (2015). R: A Language and Environment for Statistical Computing. Vienna: R Foundation for Statistical Computing.1

Redmond, M. D., Forcella, F., and Barger, N. N. (2012). Declines in pinyon pine cone production associated with regional warming. Ecosphere 3, 1-14. doi: 10.1890/ES12-00306.1

Rockwell, C. A., Guariguata, M. R., Menton, M., Quispe, E. A., Quaedvlieg, J., Warren-Thomas, E., et al. (2017). Spatial distribution of Bertholletia excelsa in selectively logged forests of the Peruvian Amazon. J. Trop. Ecol. 33, 1-14. doi: 10.1017/S0266467416000614

Rodenhouse, N. L., Sillett, T. S., Doran, P. J., and Holmes, R. T. (2003). Multiple density-dependence mechanisms regulate a migratory bird population during the breeding season. Proc. R. Soc. B Biol. Sci. 270, 2105-2110. doi: 10.1098/rspb. 2003.2438

Rodrigues, A. C., Villa, P. M., and Neri, A. V. (2019). Fine-scale topography shape richness, community composition, stem and biomass hyperdominant species in Brazilian Atlantic forest. Ecol. Indic. 102, 208-217. doi: 10.1016/j.ecolind.2019. 02.033

Rozendaal, D. M. A., and Zuidema, P. A. (2011). Dendroecology in the tropics: a review. Trees 25, 3-16. doi: 10.1007/s00468-010-0480-483

Rutishauser, E., Hérault, B., Baraloto, C., Blanc, L., Descroix, L., Sotta, E. D., et al. (2015). Rapid tree carbon stock recovery in managed Amazonian forests. Curr. Biol. 25, R787-R788. doi: 10.1016/j.cub.2015.07.034

Saatchi, S., Houghton, R. A., Dos Santos, Alvalá, R. C., Soares, J. V., and Yu, Y. (2007). Distribution of aboveground live biomass in the Amazon basin. Glob. Chang. Biol. 13, 816-837. doi: 10.1111/j.1365-2486.2007.01323.x

Schöngart, J., Gribel, R., Ferreira, da Fonseca-Junior, S., and Haugaasen, T. (2015). Age and growth patterns of brazil nut trees (Bertholletia excelsa Bonpl .) in Amazonia. Brazil. Biotropica 47, 550-558. doi: 10.1111/btp.12243

Selaya, N. G., Zuidema, P. A., Baraloto, C., Vos, V. A., Brienen, R. J. W., Pitman, N., et al. (2017). Economically important species dominate aboveground carbon storage in forests of southwestern Amazonia. Ecol. Soc. 22:40.

Shackleton, S., Delang, C. O., and Angelsen, A. (2011). "From subsistence to safety nets and cash income: exploring the diverse values of non-timber forest products for livelihoods and poverty alleviation," in Non-timber Forest Products in the Global Context, eds S. Shackleton, C. Shackleton, P. Shanley (Berlin: Springer), 55-81. doi: 10.1007/978-3-642-17983-9_3

Shepard, G., and Ramirez, H. (2011). " Made in Brazil ": human dispersal of the Brazil Nut (Bertholletia excelsa, Lecythidaceae) in Ancient Amazonia. Econ. Bot. 65, 44-65. doi: 10.1007/s12231-011-9151-6

Slot, M., Rey-Sánchez, C., Gerber, S., Lichstein, J. W., Winter, K., and Kitajima, K. (2014). Thermal acclimation of leaf respiration of tropical trees and lianas: response to experimental canopy warming, and consequences for tropical forest carbon balance. Glob. Chang. Biol. 20, 2915-2926. doi: 10.1111/gcb. 12563

Staggemeier, V. G., Cazetta, E., and Morellato, L. P. C. (2017). Hyperdominance in fruit production in the Brazilian Atlantic rain forest: the functional role of plants in sustaining frugivores. Biotropica 49, 71-82. doi: 10.1111/btp. 12358 
Staudhammer, C. L., Wadt, H. O., and Kainer, K. A. (2013). Tradeoffs in basal area growth and reproduction shift over the lifetime of a long-lived tropical species. Oecologia 173, 45-57. doi: 10.1007/s00442-013-2603-2601

Strand, J., Soares-Filho, B., Costa, M. H., Oliveira, U., Ribeiro, S. C., Pires, G. F., et al. (2018). Spatially explicit valuation of the Brazilian Amazon Forest's Ecosystem Services. Nat. Sustain. 1, 657-664. doi: 10.1038/s41893-018-01 75-170

Strobl, C., Boulesteix, A.-L., Zeileis, A., and Hothorn, T. (2007). Bias in random forest variable importance measures: illustrations, sources and a solution. BMC Bioinform. 8:25. doi: 10.1186/1471-2105-8-25

Swinfield, T., Lewis, O. T., Bagchi, R., and Freckleton, R. P. (2012). Consequences of changing rainfall for fungal pathogen-induced mortality in tropical tree seedlings. Ecol. Evol. 2, 1408-1413. doi: 10.1002/ece3.252

Talley, S. M., Coley, P. D., and Kursar, T. A. (2002). The effects of weather on fungal abundance and richness among 25 communities in the Intermountain West. BMC Ecol. 2:7. doi: 10.1186/1472-6785-2-7

ter Steege, H., Pitman, N. C. A., Sabatier, D., Baraloto, C., Salomão, R. P., Guevara, J. E., et al. (2013). Hyperdominance in the Amazonian tree flora. Science 342:1243092. doi: 10.1126/science. 1243092

Thomas, E., Alcazar Caiceda, C., Loo, J., and Kindt, R. (2014). The distribution of the Brazil nut (Bertholletia excelsa) through time: from range contraction in glacial refugia, over human-mediated expansion, to anthropogenic climate change. Bol. do Mus. Para. Emílio Goeldi. Ciências Nat. 9 , 267-291.

Thomas, E., Alcázar Caicedo, C., McMichael, C. H., Corvera, R., and Loo, J. (2015). Uncovering spatial patterns in the natural and human history of Brazil nut (Bertholletia excelsa) across the Amazon Basin. J. Biogeogr. 42, 1367-1382. doi: $10.1111 /$ jbi.12540

Thomas, E., Atkinson, R., and Kettle, C. (2018). Fine-scale processes shape ecosystem service provision by an Amazonian hyperdominant tree species. Sci. Rep. 8:11690. doi: 10.1038/s41598-018-29886-29886

Thomas, E., Valdivia, J., Alcázar Caicedo, Carolina Quaedvlieg, J., Wadt, L. H. O., and Corvera Gorminger, R. (2017). NTFP harvesters as citizen scientists: validating traditional and crowdsourced knowledge on seed production of Brazil nut trees in the Peruvian Amazon. PLoS One 8:e0183743. doi: 10.1371/ journal.pone. 0183743

Thompson, S., Alvarez-Loayza, P., Terborgh, J., and Katul, G. (2010). The effects of plant pathogens on tree recruitment in the Western Amazon under a projected future climate: a dynamical systems analysis. J. Ecol. 98, 1434-1446. doi: 10. 1111/j.1365-2745.2010.01726.x

Uriarte, M., Condit, R., Canham, C. D., and Hubbell, S. P. (2004). A spatially explicit model of sapling growth in a tropical forest: does the identity of neighbours matter? J. Ecol. 92, 348-360. doi: 10.1111/j.0022-0477.2004. 00867.x
Uriarte, M., Muscarella, R., and Zimmerman, J. K. (2018). Environmental heterogeneity and biotic interactions mediate climate impacts on tropical forest regeneration. Glob. Chang. Biol. 24, e692-e704. doi: 10.1111/gcb.14000

Venables, W. N., and Ripley, B. D. (2002). Modern Applied Statistics with S. 4th Edn. New York, NY: Springer.

Vieira, S., Trumbore, S., Camargo, P. B., Selhorst, D., Chambers, J. Q., Higuchi, N., et al. (2005). Slow growth rates of Amazonian trees: consequences for carbon cycling. Proc. Natl. Acad. Sci. U S A. 102, 18502-18507. doi: 10.1073/pnas. 0505966102

Wadt, L. H. O., Kainer, K., and Gomessilva, D. (2005). Population structure and nut yield of a stand in Southwestern Amazonia. For. Ecol. Manag. 211, 371-384. doi: 10.1016/j.foreco.2005.02.061

Wagner, F., Rossi, V., Aubry-Kientz, M., Bonal, D., Dalitz, H., Gliniars, R., et al. (2014). Pan-tropical analysis of climate effects on seasonal tree growth. PLoS One 9:e92337. doi: 10.1371/journal.pone.0092337

Wagner, F. H., Hérault, B., Bonal, D., Stahl, C., Anderson, L. O., Baker, T. R., et al. (2016). Climate seasonality limits leaf carbon assimilation and wood productivity in tropical forests. Biogeosciences 13, 2537-2562. doi: 10.5194/bg13-2537-2016

Way, D. A., and Oren, R. A. M. (2010). Differential responses to changes in growth temperature between trees from different functional groups and biomes: a synthesis of data. Tree Physiol. 30, 669-688. doi: 10.1093/treephys/tpq015

Winfree, R., Fox, J. W., Williams, N. M., Reilly, J. R., and Cariveau, D. P. (2015). Abundance of common species, not species richness, drives delivery of a real-world ecosystem service. Ecol. Lett. 18, 626-635. doi: 10.1111/ele.12424

Zhang, J., Hao, Z., Sun, I.-F., Song, B., Ye, J., Li, B., et al. (2009). Density dependence on tree survival in an old- growth temperate forest in northeastern China. Ann. For. Sci. 66:204. doi: 10.1051/forest/2008086

Zuleta, D., Russo, S. E., Barona, A., Barreto-Silva, J. S., Cardenas, D., Castaño, N., et al. (2018). Importance of topography for tree species habitat distributions in a terra firme forest in the Colombian Amazon. Plant Soil. 450, 133-149. doi: $10.1007 / \mathrm{s} 11104-018-3878-3870$

Conflict of Interest: The authors declare that the research was conducted in the absence of any commercial or financial relationships that could be construed as a potential conflict of interest.

Copyright (C) 2021 Thomas, Jansen, Chiriboga-Arroyo, Wadt, Corvera-Gomringer, Atkinson, Bonser, Velasquez-Ramirez and Ladd. This is an open-access article distributed under the terms of the Creative Commons Attribution License (CC BY). The use, distribution or reproduction in other forums is permitted, provided the original author(s) and the copyright owner(s) are credited and that the original publication in this journal is cited, in accordance with accepted academic practice. No use, distribution or reproduction is permitted which does not comply with these terms. 